University of South Florida

DIGITAL COMMONS

Digital Commons @ University of

@ UNIVERSITY OF SOUTH FLORIDA

South Florida

4-15-1987

\title{
Further Studies on the Response of the Equatorial Thermocline in the Atlantic Ocean to the Seasonally Varying Trade Winds
}

\author{
Robert H. Weisberg \\ University of South Florida, weisberg@usf.edu \\ T. Y. Tang \\ University of South Florida
}

Follow this and additional works at: https://digitalcommons.usf.edu/msc_facpub

Part of the Marine Biology Commons

\section{Scholar Commons Citation}

Weisberg, Robert H. and Tang, T. Y., "Further Studies on the Response of the Equatorial Thermocline in the Atlantic Ocean to the Seasonally Varying Trade Winds" (1987). Marine Science Faculty Publications. 69.

https://digitalcommons.usf.edu/msc_facpub/69

This Article is brought to you for free and open access by the College of Marine Science at Digital Commons @ University of South Florida. It has been accepted for inclusion in Marine Science Faculty Publications by an authorized administrator of Digital Commons @ University of South Florida. For more information, please contact digitalcommons@usf.edu. 


\title{
Further Studies on the Response of the Equatorial Thermocline in the Atlantic Ocean to the Seasonally Varying Trade Winds
}

\author{
R. H. WEISBERG AND T. Y. TANG \\ Department of Marine Science, University of South Florida, St. Petersburg
}

\begin{abstract}
Upper ocean temperature data obtained during the Seasonal Response of the Equatorial Atlantic experiment and the Francais Ocean et Climat dans l'Atlantique Equatorial program are used to describe the variations of the thermocline observed along the equator from February 1983 to September 1984. In response to rapid seasonal changes in zonal wind stress, the thermocline underwent sequences of upwelling followed by downwelling or conversely, depending upon whether the winds were intensifying or relaxing. These sequences increased systematically in magnitude and duration to the east. Both the sequential behavior and its zonal inhomogeneity represent departures from the slowly varying and in-phase climatological description of the annual thermocline response. An analytical, reduced-gravity, equatorial long wave model forced by zonal wind stress distributions representative of the variations observed along the equator was employed to reconcile the differences between the 1983-1984 synoptic measurements and the climatologically averaged description. Qualitative agreements between the model results and the data were found for many salient features of the annual cycle, including the zonal pressure gradient calculated by finite difference. The features in the model arise as interference patterns between directly forced and reflected Kelvin and long Rossby waves that are generated with each change in the wind stress. The manner in which the wind stress changes from year to year is therefore crucial to the equatorial ocean's response.
\end{abstract}

\section{INTRODUCTION}

The importance of tropical ocean sea surface temperature (SST) in global climate has led to several measurement programs aimed at understanding the response of the upper ocean currents and temperature fields to forcing by the surface wind stress. Understanding the ocean's dynamical response is a necessary step in developing coupled ocean-atmosphere models, since SST in the tropics is largely controlled by ocean dynamics. The recently completed Seasonal Response of the Equatorial Atlantic (SEQUAL) experiment and the Francais Ocean et Climat dans l'Atlantique Equatorial (FOCAL) program have provided a basin-wide and synoptic set of measurements for describing the evolution of the annual cycle in the equatorial Atlantic Ocean.

SEQUAL and FOCAL were predicated upon climatologically averaged historical ship data showing distinct annual cycles in surface wind stress, SST, surface dynamic topography, and the pressure gradients associated with the equatorial current systems. Lacking were the details of the transitions that occurred between the seasons of weak and strong winds. Figure 1 shows an overview of the SEQUAL and FOCAL field programs, which included several different moored and shipborne measurement systems (e.g., see "The Oceanography Report", Eos Transactions, $A G U$, volume 63, page 218, 1982, and Geophysical Research Letters, volume 11, pages 713-804, 1984). Here we will be concerned primarily with upper ocean temperature data obtained from surface buoyed current meter moorings deployed along the equator at $28 \mathrm{~W}, 24 \mathrm{~W}, 15 \mathrm{~W}$, and 4W from February 1983 to September 1984. These data provide two realizations of the thermocline's response to the seasonal intensification of zonal wind stress and one realization of the thermocline's response to the seasonal relaxation that occurred in between. Section 2 will describe the evolution of these responses and will point out several fundamental depar-

Copyright 1987 by the American Geophysical Union.

Paper number 6C0744.

0148-0227/87/006C-0744\$05.00 tures observed between the synoptic and climatologically averaged data. Rather than a slowly varying annual harmonic response as implied by the climatology, we will show that the annual cycle consists of upwelling and downwelling (or conversely) sequences that develop systematically and inhomogeneously along the equator following rapid and large-scale changes in zonal wind stress.

Weisberg [1984] presented a similar description based upon the response to the wind stress intensification observed in the spring of 1983 by the first of the three SEQUAL mooring deployments. Weisberg and Tang [1985] then employed an analytical, linear, reduced-gravity, equatorially trapped long wave model driven by a hierarchy of easterly wind stress forcing functions representative of the Atlantic to compare the integrated nature of the forced long wave response with the data. Qualitative agreement was found with upwelling and downwelling sequences increasing systematically to the east within the forced region. It was concluded that the rapidly varying nature of the wind stress in a given year is crucial to the development of the response in that year. We continue along the same vein in the present paper to investigate the subsequent relaxation and intensification responses. The analytical model is modified to include dissipation and an expanded sequence of zonal wind stress changes, thus allowing for long-term integrations. The model is tested in section 3 under switched-on and periodic forcing. Model runs are then presented in section 4 using zonal wind stress distributions that embody in a simplified manner the temporal and zonal variations that were observed during 1983-1984. Qualitative agreement was found between the patterns of the observed temperature variations and the interference patterns set up by the directly forced and reflected Kelvin and long Rossby waves of the model. The evolution of the zonal pressure gradient is discussed, and a comparison is made between the zonal pressure gradient computed by finite difference between $28 \mathrm{~W}$ and $4 \mathrm{~W}$ from both the model and the moored temperature data. Section 5 shows the effects that higher frequency wind stress oscillations have upon the long wave model response. 


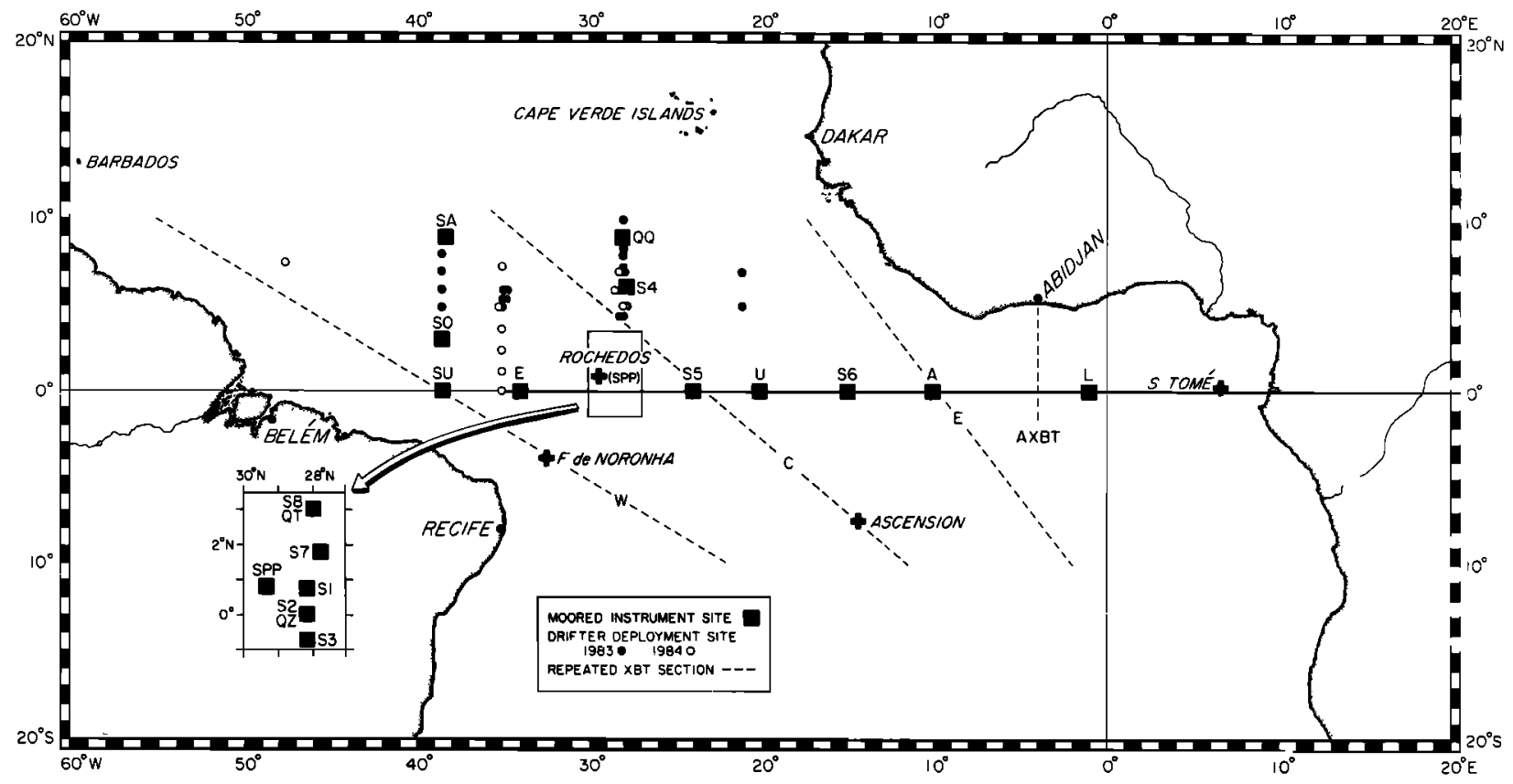

Fig. 1. Schematic of the SEQUAL/FOCAL field program showing positions of the various measurement systems.

These add in a frequency dependent manner, but they do not alter the overall character of the annual cycle. Section 6 provides a summary.

\section{BACKGROUND}

\section{Observations}

Climatologically averaged monthly fields of surface wind stress and ocean hydrography have played central roles in the description of the annual variability of the equatorial Atlantic Ocean. These fields derive from the historical ship reports of both merchant vessels and oceanographic expeditions. Hastenrath and Lamb [1977] and Hellerman [1979] present the climatological surface wind stress distributions. The principal features are the northeast and southeast trade winds separated by the Intertropical Convergence Zone (ITCZ) over most of the basin and southerly to southwesterly winds over the eastern portion of the Gulf of Guinea. The winds along the equator tend to be most intense during summer when the ITCZ is positioned furthest to the north and weakest in winter when the ITCZ straddles the equator. The transitions from strong to weak winds, and conversely, occur slowly in the climatology. Merle [1978, 1980] and Merle and Arnault [1985] present the climatologically averaged ocean hydrographic fields, and together with the studies of Katz [1981] and Garzoli and Katz [1983], they describe the annual cycles of the major dynamic height ridges and troughs that comprise the tropical Atlantic sea surface topography. The overall picture emergent from these studies is one of a distinct and slowly varying annual cycle having the oceanographic parameters nearly in phase with the winds. Regional differences in the annual cycle have been noted, including primary and secondary upwelling seasons in the Gulf of Guinea [e.g., Merle and Arnault, 1985], and

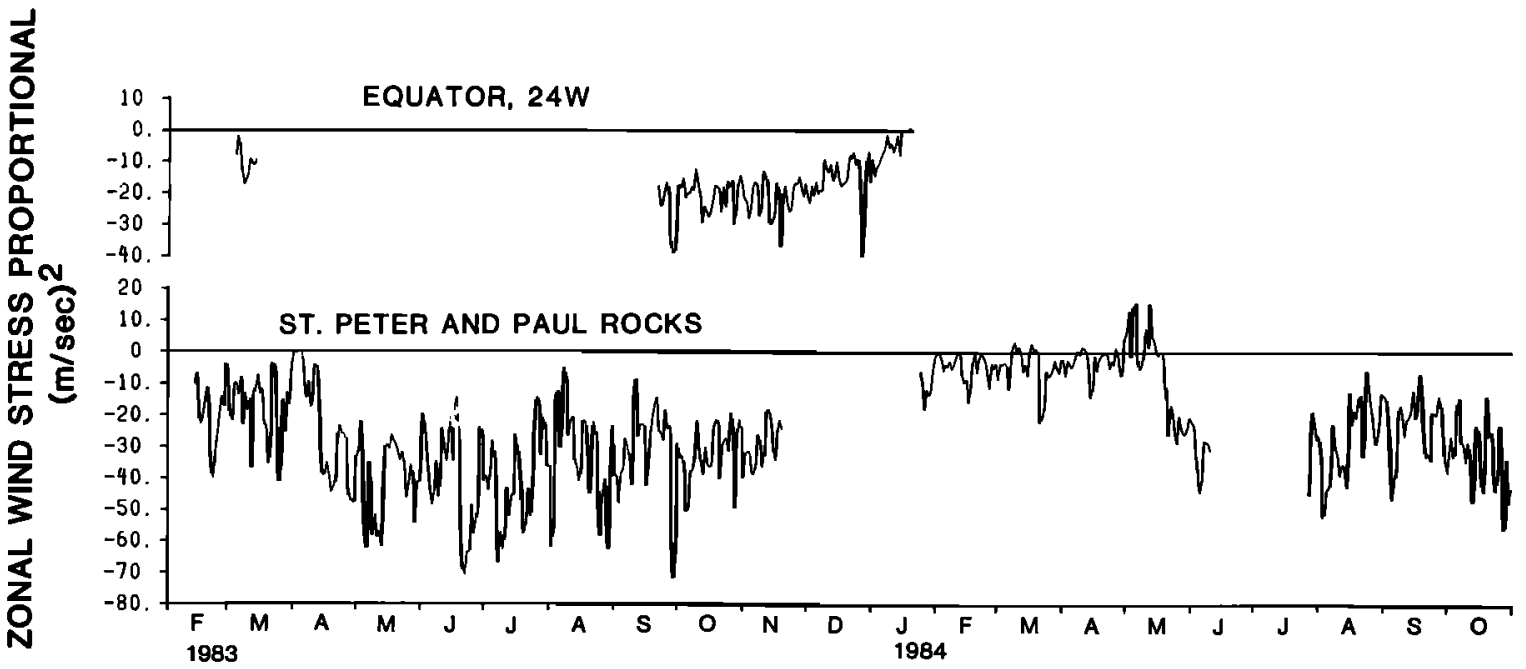

Fig. 2. Low-pass filtered time series of the proportional of easterly wind stress observed on St. Peter and Paul Rocks and on a moored buoy at the equator, $24 \mathrm{~W}$. 


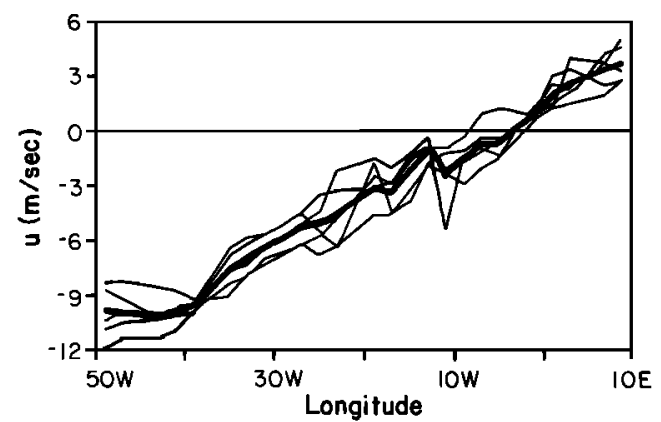

Fig. 3. Distributions along the equator of the zonal wind velocity component observed in September 1978 by Seasat (D. Halpern, personal communication, 1986). The thin lines represent averages over two-degree squares centered on the equator each during 3-day nonoverlapping periods. The thick line is the average over the 15 days of record.

these have prompted several data analysis and modeling studies that are reviewed by Busalacchi and Picaut [1983].

In contrast to the climatologically averaged description, the wind stress variations in any given year may occur much more rapidly. This is true of the historical ship wind data set from which the climatology derives [e.g., Servain et al., 1982], and it also appears in the first in situ surface wind time series collected at St. Peter and Paul Rocks (SPPR) presented by Garzoli et al. [1982]. Averaging records over many years, each with varying phase and duration for the annual cycle, necessarily results in a slowly varying description even when the departures from year to year are large.

The rapidly varying nature of the surface wind stress changes in a given year, and the interannual variations in these changes are now becoming more evident from the SEQUAL and FOCAL data sets. Figure 2 shows time series for the zonal component of surface wind stress collected at SPPR (S. L. Garzoli and E. J. Katz, personal communication, 1986) and at a moored buoy located on the equator at $24 \mathrm{~W}$ (R. Payne, personal communication, 1986). The data have been low-pass filtered with a Gaussian-shaped weighting function of standard deviation and sampling interval equal to 8 hours to remove semidiurnal and higher frequency oscillations. While oscillations exist over a broad range of frequencies, the underlying annual cycle stands out clearly. At SPPR during 1983 the easterlies increased rapidly over the course of a few weeks to a month beginning mid-April and then remained well developed through the November record gap. Upon resumption of the record, the winds were very weak and remained so until mid-May 1984, when they again intensified even more rapidly than in the year before. Immediately preceding the seasonal intensifications of these years, short-lived events are observed wherein the already weak easterlies weakened further or reversed to become westerlies. During 1983, at least, the short-lived relaxation event appeared to be of basin-wide extent with observations at $24 \mathrm{~W}$, $15 \mathrm{~W}$, and $4 \mathrm{~W}$, although only speed was available at $24 \mathrm{~W}$ and 4W [Payne, 1984, and C. Colin, personal communication, 1986]. The $24 \mathrm{~W}$ wind record fills in the SPPR record gap and shows that the primary seasonal relaxation in easterly wind stress also occurred rapidly. Beginning mid-December 1983, we observe a decrease to zero over an interval slightly longer than a month. The limited wind data available from the equatorial $15 \mathrm{~W}$ and $4 \mathrm{~W}$ moorings have further shown that the easterlies were generally weak at these locations and that they reversed to become westerlies at $4 \mathrm{~W}$ during the 1983 fall through 1984 winter seasons. This is in keeping with the zonal distribution implied by the climatology. It also agrees with the synoptic picture obtained by Seasat during the high-wind season of 1978 as shown in Figure 3 (D. Halpern, personal communication, 1986). The zonal component of wind velocity in this figure is distributed linearly along the equator with maximum easterly values at the Brazilian coast, a node at around $5 \mathrm{~W}$, and maximum westerly values at the African coast.

Variations in upper ocean temperature in response to the wind are evident in the SEQUAL and FOCAL moored current meter data sets. Figure 4 shows the temperature at $75-\mathrm{m}$ depth collected on the equator at $24 \mathrm{~W}$ from February 1983 through September 1984, low-pass filtered as in Figure 2. Coincident with the rapid intensification of easterly wind stress occurring in mid-April 1983, we observe a rapid decrease in temperature continuing for around 1 month. Although the easterly wind stress remains strong on into winter, the temperature at $75 \mathrm{~m}$ begins to increase early in June and continues to do so through August. It then remains relatively steady until the easterly wind stress begins to relax in mid-December 1983 . At this time we observe an increase in temperature, followed by a decrease with decreasing temperature persisting throughout the period of weak winds. The winds and upper ocean temperature variations have now completed one annual cycle. A second annual cycle begins with the onset of rapidly increasing easterly wind stress in mid-May 1984 . Once again we observe a decrease in temperature at $75 \mathrm{~m}$, continuing for around 1 month, followed by an increase to what would appear to be a relatively steady value in September 1984 . Short-lived peaks in temperature are also observed following the short-lived wind stress relaxation events. The one in midApril 1983 is particularly well pronounced. The foregoing description implies that in conjunction with rapid and largescale changes in easterly wind stress the temperature within the thermocline undergoes sequences of decreasing (increasing)

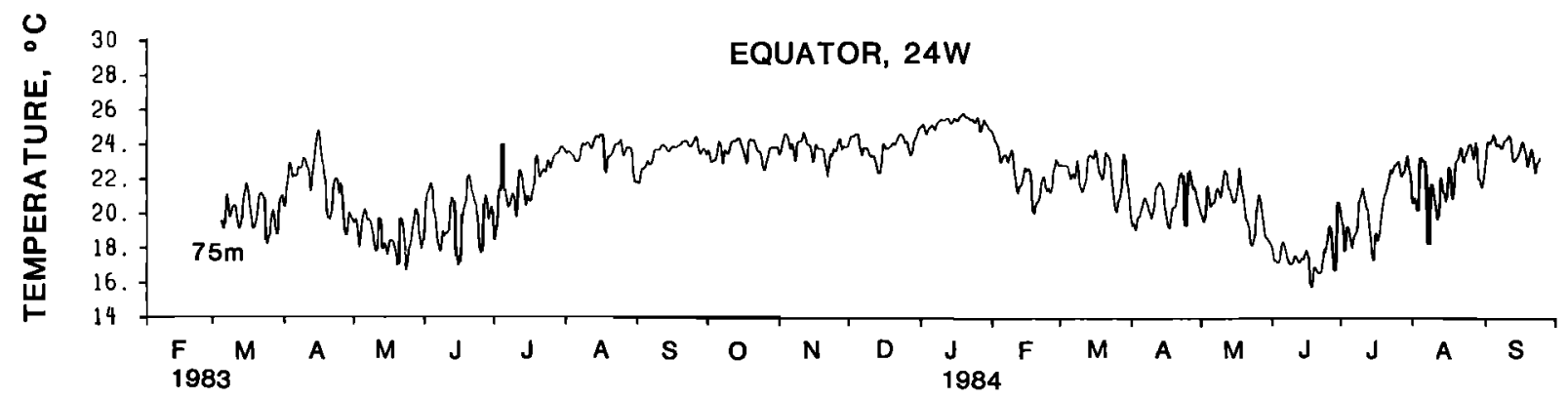

Fig. 4. Low-pass filtered temperature time series from $75-\mathrm{m}$ depth measured on the equator at $24 \mathrm{~W}$. 


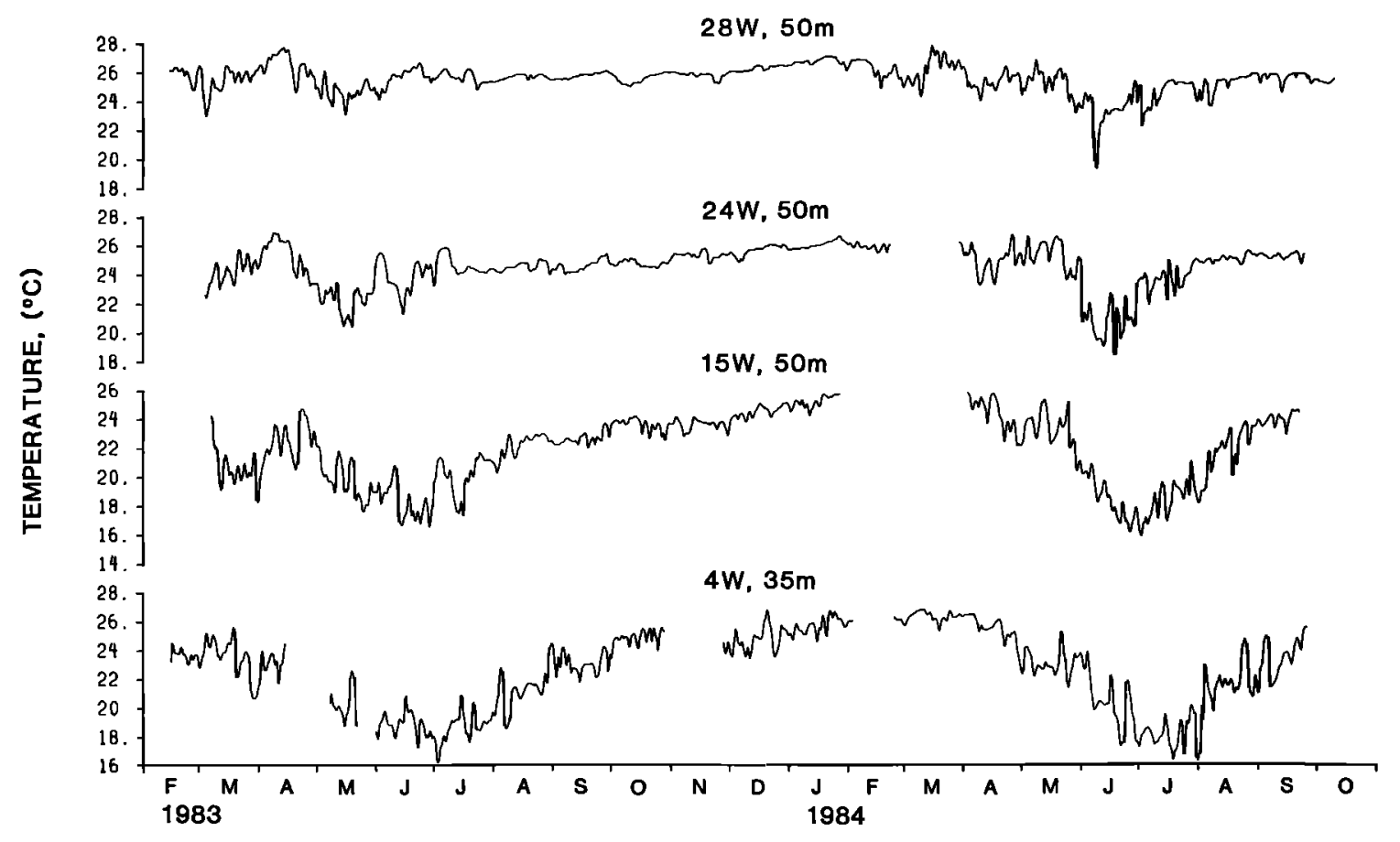

Fig. 5. Low-pass filtered temperature time series from $50 \mathrm{~m}$ along the equator at $28 \mathrm{~W}, 24 \mathrm{~W}$, and $15 \mathrm{~W}$ and from $35 \mathrm{~m}$ at $4 \mathrm{~W}$.

followed by increasing (decreasing) values, depending upon whether the easterly stress is intensifying or relaxing.

Temperature times series from the other longitudes sampled show that the annual cycle evolves inhomogeneously along the equator. Figure 5 presents low-pass filtered temperature time series at $50-\mathrm{m}$ depth from $28 \mathrm{~W}, 24 \mathrm{~W}$, and $15 \mathrm{~W}$ and at $35-\mathrm{m}$ depth from $4 \mathrm{~W}$. While these data are similar in that they all undergo a sequential decrease and increase in temperature following the easterly wind stress intensifications of both 1983 and 1984, what sets them apart is the systematic increase to the east in both the magnitude and duration of these sequences.

The temperature variations at these specific depths are indicative of the overall temperature variations within the thermocline. Figures 6 and 7 show isotherm depths as a function of time on the equator at $28 \mathrm{~W}$ and $4 \mathrm{~W}$, respectively, along with the vertically integrated temperature. For the purposes of contour plotting, these data have been further low-pass filtered to exclude oscillations at time scales shorter than 10 days using a truncated Fourier transform. The entire thermocline is observed to heave up and down in unison over the depth ranges sampled $(200 \mathrm{~m}$ at $28 \mathrm{~W}$ and $110 \mathrm{~m}$ at $4 \mathrm{~W})$. The vertically integrated temperature that is proportional to heat content varies inversely with the overall movement of the isotherms. As the isotherms upwell, the heat content decreases and conversely.

At $28 \mathrm{~W}$ we observe a sequence of upwelling followed by downwelling beginning with the onset of increasing easterly wind stress both in 1983 and in 1984. This sequence lasts for 2-3 months, followed by a period in which the thermocline attains a relative equilibrium position. In 1983 this equilibrium lasted for around 4 months. Beginning mid-December 1983, when the easterly wind stress started to decrease, we observe a sequence of downwelling followed by upwelling. While some license has been taken in neglecting higher frequency oscillations, which at any given depth may have simi- lar magnitude as the annual cycle, the annual cycle as described is the underlying feature as demonstrated by the heat content time series.

Similar behaviors are observed at $4 \mathrm{~W}$ along with some distinct differences. First, while the upwelling/downwelling sequences occur in both years as at $28 \mathrm{~W}$, their durations are longer and the range of the $20^{\circ} \mathrm{C}$ isotherm is larger. Second, the downwelling at $4 \mathrm{~W}$ following the mid-December decrease in easterly wind stress is much more pronounced than it is at $28 \mathrm{~W}$, with the thermocline at $4 \mathrm{~W}$ continuing to deepen after the thermocline at $28 \mathrm{~W}$ has begun to shoal. Thus the response to decreasing easterly wind stress is also zonally inhomogeneous.

We may now summarize the salient features of the annual thermocline variability observed along the equator in the Atlantic Ocean during 1983-1984. In response to large-scale changes in easterly wind stress, the thermocline underwent sequences of upwelling followed by downwelling or conversely, depending upon whether the wind stress increased or decreased. The response to increased wind stress in 1984 evolved somewhat more rapidly than that in 1983 . These sequences increased systematically to the east both in duration and magnitude. This resulted in a relative state of equilibrium for the thermocline at $28 \mathrm{~W}$ over several months in 1983 after the wind stress had intensified. At $4 \mathrm{~W}$ we observed a very pronounced downwelling following the decrease in easterly wind stress that began in mid-December 1983. These observations offer distinct spatial and temporal patterns of thermocline variability in the equatorial Atlantic that may be used as a basis for comparison with models of the ocean's response. It is also of interest to note here that upwelling in the Gulf of Guinea did not simply commence with the onset of increased easterlies in the western Atlantic, as several previous studies have implied. Instead, upwelling appears to proceed in two stages, starting with the relaxation in easterly wind stress from the previous year and continuing with the increase in easterly 


\section{EQUATOR, 28W}
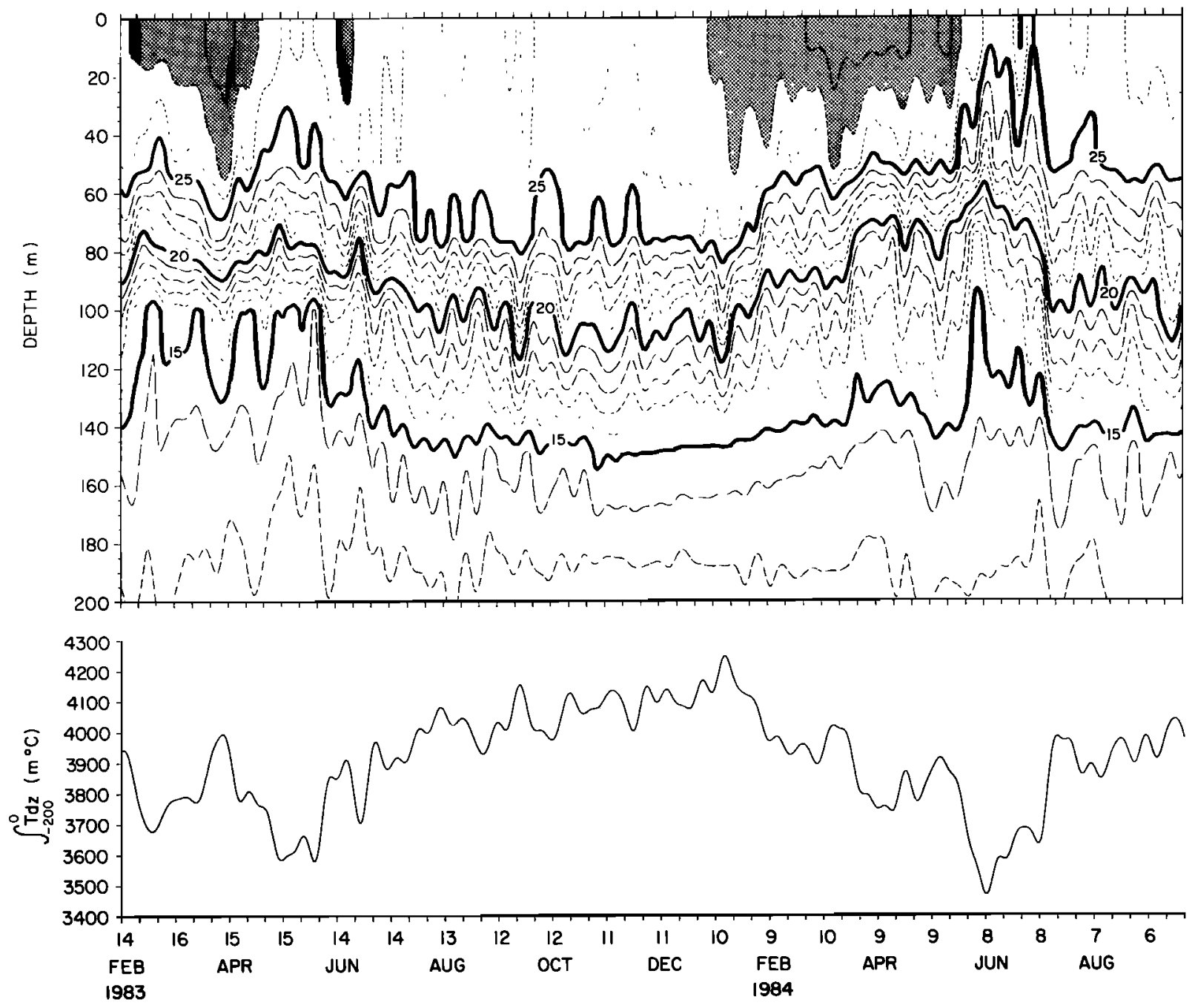

Fig. 6. Temperature as a function of depth and tıme along with its vertical integral from the equator at $28 \mathrm{~W}$.

wind stress of the present year. For example, the upwelling at 4W in 1984 began in March, roughly 2 months before the easterlies were observed to increase at SPPR.

\section{Theory}

The generation of equatorial currents by changes in wind stress and the role of equatorially trapped waves in adjusting the ocean pressure field to the wind field were reviewed by Moore and Philander [1977]. Cane and Sarachik [1976, 1977] showed that the primary mechanisms for the adjustment at low frequency are the Kelvin and long Rossby waves excited by the zonal component of surface wind stress. Similar findings were obtained in the numerical and analytical reducedgravity model studies of Hurlburt et al. [1976] and McCreary [1976], respectively, and these were expanded upon, using a multilevel numerical model run linearly and nonlinearly for switched-off and switched-on zonal wind stress by Philander and Pacanowski [1980] and Philander [1981], respectively. In relation to the annual cycle, a series of investigations considered periodic forcing using simple harmonic functions. Cane and Sarachik [1981] employed a linear analytical long wave model, and Philander and Pacanowski [1981] employed linear and nonlinear multilevel numerical models. These stud- ies showed an annual thermocline response nearly in phase with the wind stress, and the former suggested the presence of a pivot point about which the thermocline hinged, as had previously been described by Merle [1980]. McCreary et al. [1984] used a multiple-mode simple harmonic model to investigate the effects of annual wind variations in the western Atlantic on the Gulf of Guinea. These simple harmonic investigations were followed by complex periodic calculations using the climatologically averaged monthly wind stress distributions. For the equatorial Atlantic Ocean, linear single- and multiple-mode reduced-gravity numerical models were run by Busalacchi and Picaut [1983] and du Penhoat and Treguier [1984], respectively, and linear and nonlinear multilevel numerical models were run by Philander and Pacanowski [1984, 1986]. While the climatologically averaged wind stress driven models have been successful at emulating the climatologically averaged thermocline response, several fundamental differences exist between these results and the synoptic observation obtained during 1983-1984 by the SEQUAL and FOCAL programs. Figure 8 shows time series of the upper layer thickness from the linear reduced-gravity model of Busalacchi and Picaut [1983] and the vertically integrated heat from the nonlinear multilevel model of Philander and Pacanowski [1986] 


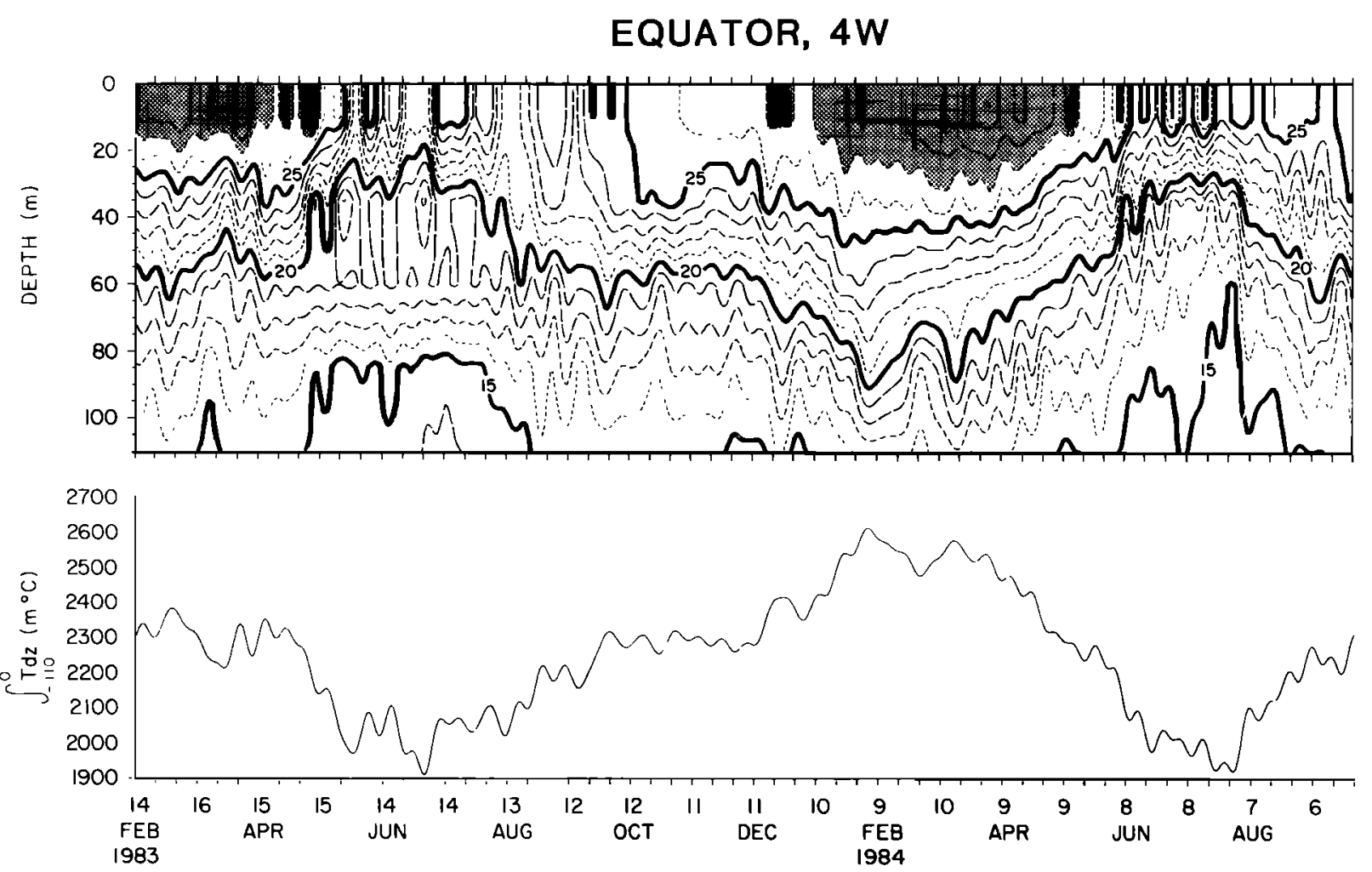

Fig. 7. Temperature as a function of depth and time along with its vertical integral from the equator at $4 \mathrm{~W}$.

sampled at the model locations of $28 \mathrm{~W}$ and $15 \mathrm{~W}$. The climatologically driven models show slowly varying responses that are nearly in phase with the forcing functions. The character of the response at $28 \mathrm{~W}$ and $15 \mathrm{~W}$ is fairly similar, with the exception of a phase shift. In comparison with the synoptic data, these model results do not show the zonally inhomogeneous upwelling/downwelling or downwelling/upwelling sequences following the onsets of intensifying or relaxing wind stress, respectively.

The present paper will depart from these previous studies

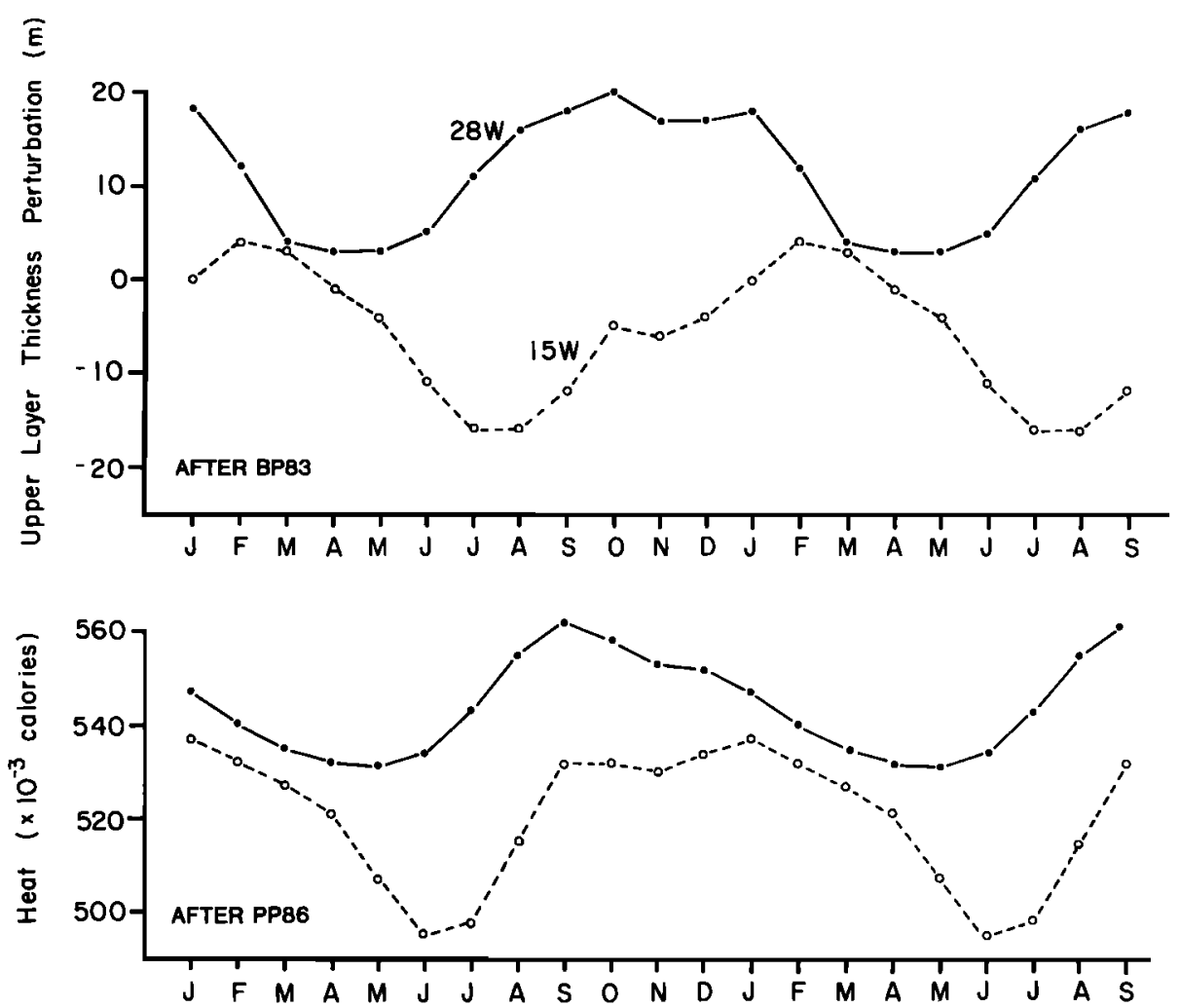

Fig. 8. The annual cycles of upper layer thickness perturbation and vertically integrated heat from the linear reducedgravity model of Busalacchi and Picaut [1983] and the nonlinear multilevel model of Philander and Pacanowski [1986], respectively. Time series are shown for model positions corresponding to $28 \mathrm{~W}$ and $15 \mathrm{~W}$. 

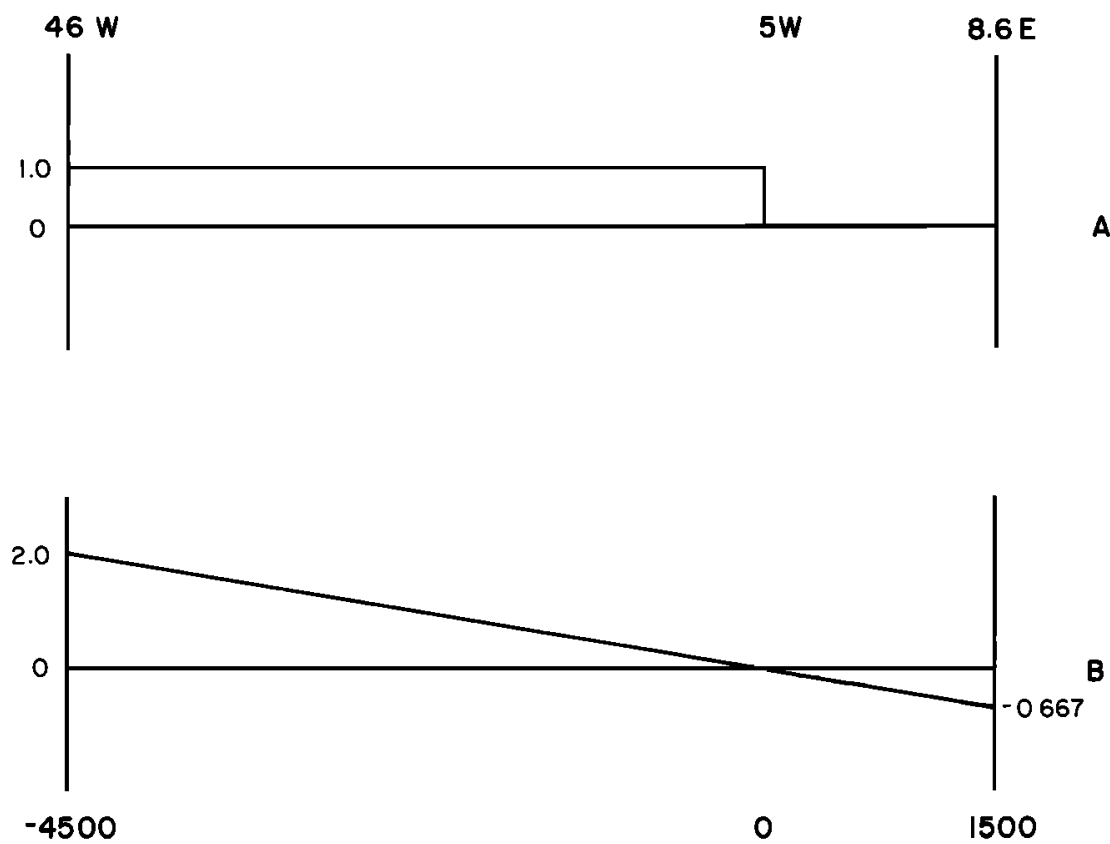

ZONAL POSITION (KM)

Fig. 9. The model domain and the zonal wind distributions used in the case $A$ and case $B$ integrations.

by utilizing a forcing function in an analytical, linear, reducedgravity, equatorial long wave model that embodies (in a very simplified fashion) the temporal and spatial variations of the zonal wind stress observed during 1983-1984. Since the model is analytical, we can trace the evolution of the thermocline response relative to both the specific changes in the wind stress and the mechanisms of the model that are affecting these changes in the thermocline response. Initial motivation for an approach of this type followed from Gill and Clarke [1974].

Since the response arises as an integral over a forced region that essentially includes the entire basin, we will focus upon the interference patterns set up by the forced and reflected waves as opposed to the propagation of individual waves. The character of these interference patterns depends upon position within the forced region and the rate of change of the wind stress relative to the time that it takes for the direct responses and their subsequent boundary reflections to evolve.

\section{Analytical Model}

We consider a linear, reduced-gravity, equatorial $\beta$-plane model forced from a state of rest by a temporally and spatially varying zonal wind stress distribution. The equations of motion are

$$
\begin{gathered}
\frac{\partial u}{\partial t}-y v+\frac{\partial h}{\partial x}=\tau-\varepsilon u \\
\frac{\partial v}{\partial t}+y u+\frac{\partial h}{\partial y}=-\varepsilon v \\
\frac{\partial h}{\partial t}+\frac{\partial u}{\partial x}+\frac{\partial v}{\partial y}=-\varepsilon h
\end{gathered}
$$

where $u$ and $v$ are the velocity components in the $x$ and $y$ directions, $h$ is the upper layer thickness perturbation, $t$ is time, $\tau$ is the zonal component of wind stress, and $\varepsilon$ is a damping parameter. The equations have been nondimensiona- lized using time and length scales $T=(c \beta)^{-1 / 2}$ and $L=$ $(c / \beta)^{1 / 2}$, where $c=\left(g^{\prime} H\right)^{1 / 2}$ is the reduced-gravity wave speed corresponding to the reduced-gravity $g^{\prime}$ and the undisturbed upper layer water depth $H$, and $\beta$ is the gradient in planetary vorticity. The analytical solution of these equations without damping is discussed in detail by Cane and Sarachik [1976, 1977]. Their procedure is to Fourier transform the equations of motion, project the forcing function onto the appropriate equatorial wave modes of the homogeneous equations that form a complete set over the interval $-\infty<y<\infty$, integrate these projections in time, and then invert the Fourier transforms using a long wave approximation. The result of the foregoing operations yields the directly forced part of the solution. These forced waves then reflect off of the meridional boundaries to yield the additional long equatorial waves that together comprise the total solution.

Dissipation in an equatorial long wave model was introduced by Gill [1980] to investigate steady motions forced by a local heat source, and this idea was expanded upon by Zebiak [1982] and Heckley and Gill [1984]. These studies used large and equal values of Rayleigh friction and Newtonian cooling in the momentum and mass conservation equations, respectively, as the simplest means of damping equatorial wave modes as they propagate away from the forced region. The $e$-folding times for the decay of the forced wave modes were only a few days. In an investigation of the semi-annual response of the equaturial Indian Ocean to semi-annual zonal wind stress forcing, Gent et al. [1983] employed a relatively small value of dissipation in the above manner. The $e$-folding time used in their multiple-mode reduced-gravity model, periodically forced at a single frequency by a spatially varying semi-annual harmonic, was chosen as 2 years to best match the available observations. No attempt has been made in any of these studies to offer a physical basis for the parameterization of dissipation by Rayleigh friction and Newtonian cooling. What makes this parameterization attractive, however, is that it provides for damping while maintaining the 


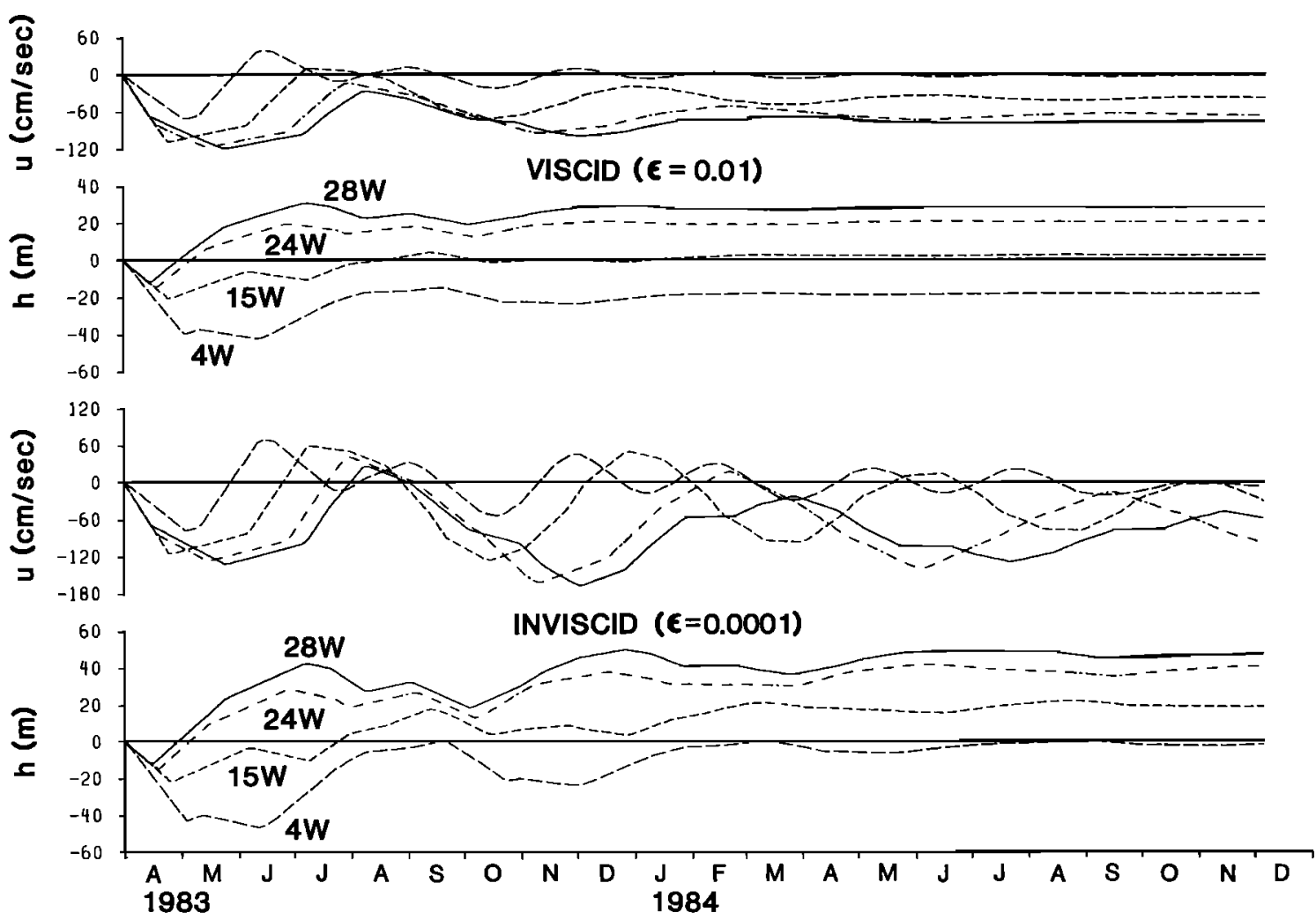

Fig. 10. Upper layer thickness perturbation and zonal velocity component calculated on the equator at $28 \mathrm{~W}, 24 \mathrm{~W}$, $15 \mathrm{~W}$, and $4 \mathrm{~W}$ under switched-on easterly wind stress forcing. Two sets of series are given, one for $\varepsilon=0.0001$, which is essentially undamped, and one for $\varepsilon=0.01$, corresponding to a dimensional $e$-folding time scale of 192 days.

form of the undamped equatorial wave solutions that can then be traced analytically through their evolution. In a real sense, dissipative losses in a forced response can occur for a variety of reasons, including eddy exchanges of momentum and heat both laterally and vertically, vertical propagation into the deep ocean, nonlinear interactions with the background currents, and imperfect reflections from meridional boundaries. Therefore once the integration time of the model becomes long compared with the propagation time for the waves comprising the solution to traverse the basin, some inclusion of dissipation seems necessary.

Weisberg and Tang [1985] hereafter referred to as WT85, employed an undamped version of the present model to develop a basis for the zonally inhomogeneous upwelling/downwelling sequence observed [Weisberg, 1984] after the first SEQUAL mooring deployment from February to September 1983. Here we build upon that calculation by adding dissipation in the form of Rayleigh friction and Newtonian cooling and by generalizing the forcing function to consist of an arbitrary sequence of linearly increasing or decreasing segments.

The forcing function has the form

$$
\tau(x, y, t)=\gamma \exp \left(-y^{2} / 2\right) X(x) F(t)
$$

where

$$
F(t)=H(t) t / T_{1}+\sum_{i=1}^{I} H\left(t-T_{i}\right)\left\{S_{i}\left(t-T_{i}\right) / T_{i}\right\}
$$

and

$$
X(x)=H(x)-H\left(x+L_{1}\right)
$$

for a uniformly distributed wind stress, or

$$
X(x)=-x\left\{H\left(x-L_{2}\right)-H\left(x+L_{1}\right)\right\}
$$

for a linearly distributed wind stress, where the $H$ 's are step functions. The parameters of the wind stress are $\gamma$ and $S_{i}$ specifying the magnitude of the variations, $T_{i}$ specifying the duration of these variations, and $L_{1}$ and $L_{2}$ specifying the fetches. Figure 9 shows the model domain and the two zonal wind distributions to be employed. A reduced-gravity wave speed of $c=160 \mathrm{~cm} / \mathrm{s}$ is used based upon the depth of the thermocline in the central equatorial Atlantic and the density difference across it, which from Figure 6 are approximately 90 $\mathrm{m}$ and $3 \sigma_{T}$ units, respectively. As will become evident later, $c=160 \mathrm{~cm} / \mathrm{s}$ is consistent with the phasing of the patterns that make up the annual cycle, and small variations about it do not significantly alter these patterns. This value is close to the phase speed for the second baroclinic mode used in the model of Busalacchi and Picaut [1983] and shown by McCreary et al. [1984] to most strongly influence the pressure field in their simple harmonic annual model. Dimensionally, the basin extends from $46 \mathrm{~W}$ to $8.6 \mathrm{E}$ for a total width of 6000 $\mathrm{km}$, and the origins of the wind stress distributions are set at $5 \mathrm{~W}$ with $L_{1}$ and $L_{2}$ equal to 4500 and $1500 \mathrm{~km}$, respectively.

Two model tests were performed. The first was to instantaneously switch on uniform easterlies in the region to the west of $5 \mathrm{~W}$ for the purposes of testing the present formulation against the simpler model of WT85 and investigating the effects of damping upon the evolution of the response. The second was to drive the model periodically with uniform east- 
erlies to the west of $5 \mathrm{~W}$. Numerical models periodically forced by climatological winds have generally been run for several years before performing analyses. The purpose for the periodic forcing test here was to investigate the effects of the responses from the previous years upon the present year of the model run.

\section{Switched-On Experiment}

To switch the winds on instantaneously at approximately $t=0$, values of $I, S_{b}$, and $\gamma$ were set equal to $1,-1$, and 0.057 , respectively, and the intensification time $T_{1}$ was chosen to be much less than 1 . Dimensionally, this value of $\gamma$ corresponds to a wind stress magnitude of $0.5 \mathrm{dyn} / \mathrm{cm}^{2}$, approximately that observed at SPPR. Figure 10 shows the resulting time series in dimensional form for $h$ and $u$ sampled along the equator at the model longitudes of $28 \mathrm{~W}, 24 \mathrm{~W}, 15 \mathrm{~W}$, and $4 \mathrm{~W}$. Two sets of time series are given, one for $\varepsilon=0.0001$, which is essentially an inviscid case, and the other for $\varepsilon=0.01$, which is a viscous case with an $e$-folding time of 192 days.

The response evolves with the growth of the directly forced waves and their subsequent boundary reflections. For simplicity, a normal form was chosen for the meridional distribution of wind stress, since it projects only onto the Kelvin wave and the first mode Rossby wave. Upon reflection, these waves result in all higher odd-mode Rossby waves, which are then retained in the solution. Qualitatively, there is little difference directly on the equator in the upper layer thickness perturbation resulting from this meridional distribution and other symmetric wind stress distributions [Cane and Sarachik, 1976; Weisberg and Tang, 1983; WT85].

In a forced wave model the response at any given point and time consists of the summation at that point of all waves present at that time. The resulting interference patterns that emerge for the nearly inviscid and the viscid cases are therefore the same with the exception of damping. The evolution of the pattern observed for $h$ in the nearly inviscid calculation of Figure 10 was discussed in relation to the individual waves that make it up over the first 5 months by WT85. Of particular interest here is the systematic increase to the east in both the magnitude and duration of the upwelling/downwelling (decreasing/increasing $h$ ) sequence following the onset of the easterly wind stress. As a check on the present formulation with damping, we note that the results over the first 5 months for this model and the previous one are identical. Over subsequent times we see the interference pattern repeat regularly but with smaller magnitude. These repetitions result from the boundary reflections, and since a Kelvin wave incident upon the eastern boundary reflects onto an infinite sum of Rossby waves with the result being a poleward energy flux [Moore, 1968], the switched-on solution tends toward an equilibrium even without damping. Damping merely hastens the process for $h$, while for $u$ the effects of damping appear more evident due to the relative magnitudes of $u$ and $h$ on the equator for the reflected Rossby waves. The evolution of $u$ in this model is very similar to the multilevel numerical model results of Philander and Pacanowski [1980]. We note that $u$ first accelerates westward under the influence of the directly forced waves and then accelerates eastward under the influence of the primary reflected waves. This reversal occurs after only 2 months at $28 \mathrm{~W}$ and even more rapidly at points further east. The process then continues with the secondary reflections, and the inter- ference patterns become more complicated as higher mode Rossby waves enter into the solution.

The repetition of the upwelling/downwelling interference pattern observed at $4 \mathrm{~W}$ from October to December occurs at the time of the second upwelling season reported in the Gulf of Guinea by Merle and Arnault [1985] from climalotogical data. While we are not suggesting that this is the explanation of the second upwelling season, these results do show that a semi-annual harmonic of the wind stress is not a necessary condition for the second upwelling. It may simply result from the reflections associated with the primary upwelling season. Philander and Pacanowski [1986] arrived at a similar conclusion.

Experimentations with other values of $\varepsilon$ were also performed. For example, increasing $\varepsilon$ to 0.1 reduces the $e$-folding scale to 19.2 days and effectively eliminates reflected waves from the solution. Using $\varepsilon=0.01$ as an intermediate case between an inviscid and an overdamped solution provides for damping while allowing reflected waves to exist over at least one round trip transit of the basin which appears to be compatible with the observations.

\section{Periodic Experiment}

From the switched-on results of Figure 10, we observed that an equilibrium response may be obtained with a nominal amount of damping. To investigate the effects of previous year wind stress variations upon a present year response under a more complicated and realistic set of changes, we ran the model periodically over 4 years. The zonal wind stress distribution was uniform to the west of $5 \mathrm{~W}$ and zero elsewhere. Temporally the wind stress varied as follows. Linearly growing westerlies were switched on for 10 days and then reversed to linearly growing easterlies for the next $\mathbf{3 0}$ days. They were then held constant until day 270 , at which time they decreased linearly to zero at day 300 and then remained zero until day 365. As described in section 2 , this sequence corresponds to the large-scale variations that were observed to occur in 1983. These wind stress variations and the resulting $h$ response due to their repetition over 4 years are shown in Figure 11 for three values of $\varepsilon$. The cases $\varepsilon=0.001$ and $\varepsilon=0.01$ are qualitatively similar. Both of these provide sufficient friction to justify a long wave approximation [e.g., Cane and Sarachik, 1981] while allowing for reflections to traverse the basin. The overdamped case $\varepsilon=0.1$ excludes reflected waves (even from the western boundary), thereby resembling an unbounded equatorial ocean response, which is unrealistic in view of the observations. In all three cases, subsequent years are very similar to the first year excepting initial conditions. Therefore the model is capable of long-term integrations given a nominal amount of friction.

\section{Results}

Two cases have been run to investigate the model responses to easterly wind stress variations that include in a very simplified way the large-scale changes that occurred between April 1983 and December 1984. The temporal variations in wind stress are the same for both cases, while the zonal distributions are different. Case A considers winds distributed uniformly to the west of $5 \mathrm{~W}$. Case B considers winds distributed linearly with a zero crossing at $5 \mathrm{~W}$. Both of these zonal distributions are shown in Figure 9. In accordance with section 2, the temporal variations are as follows. The time origin is set at 


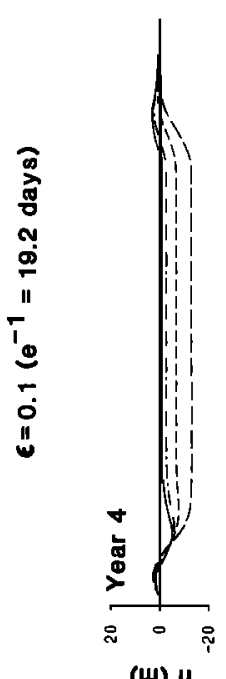

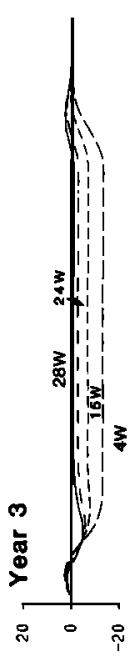

(w) 4

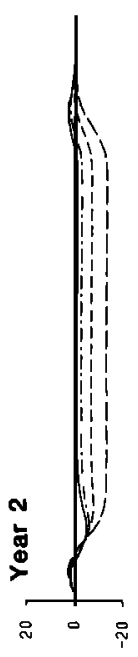

(w) 4

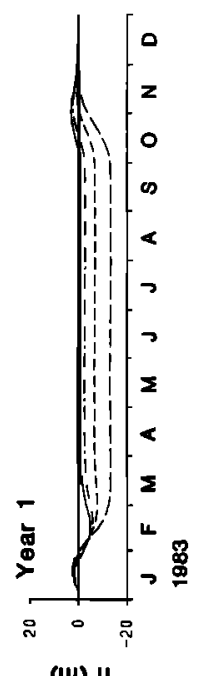

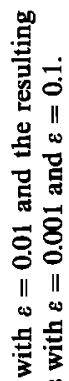
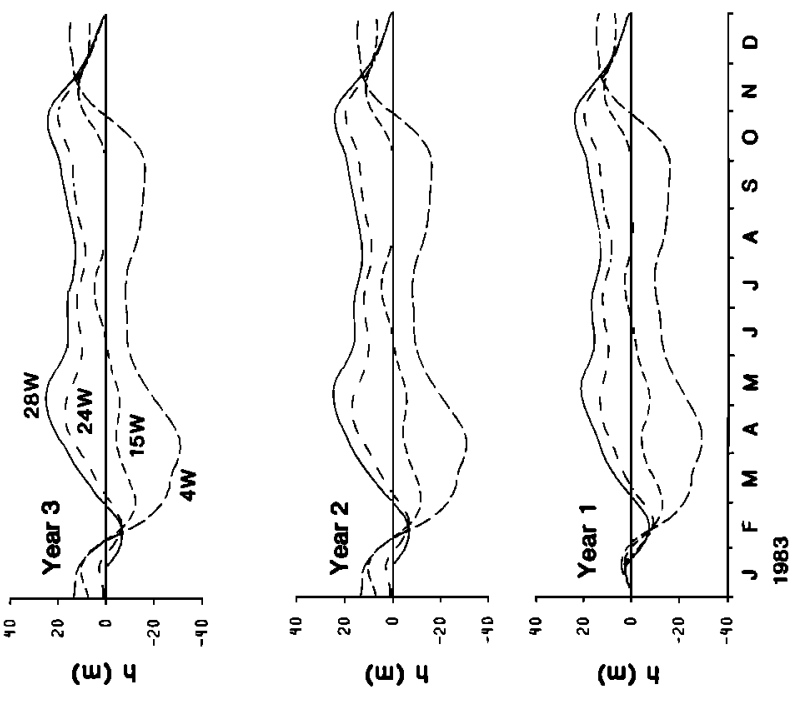

(w) 4
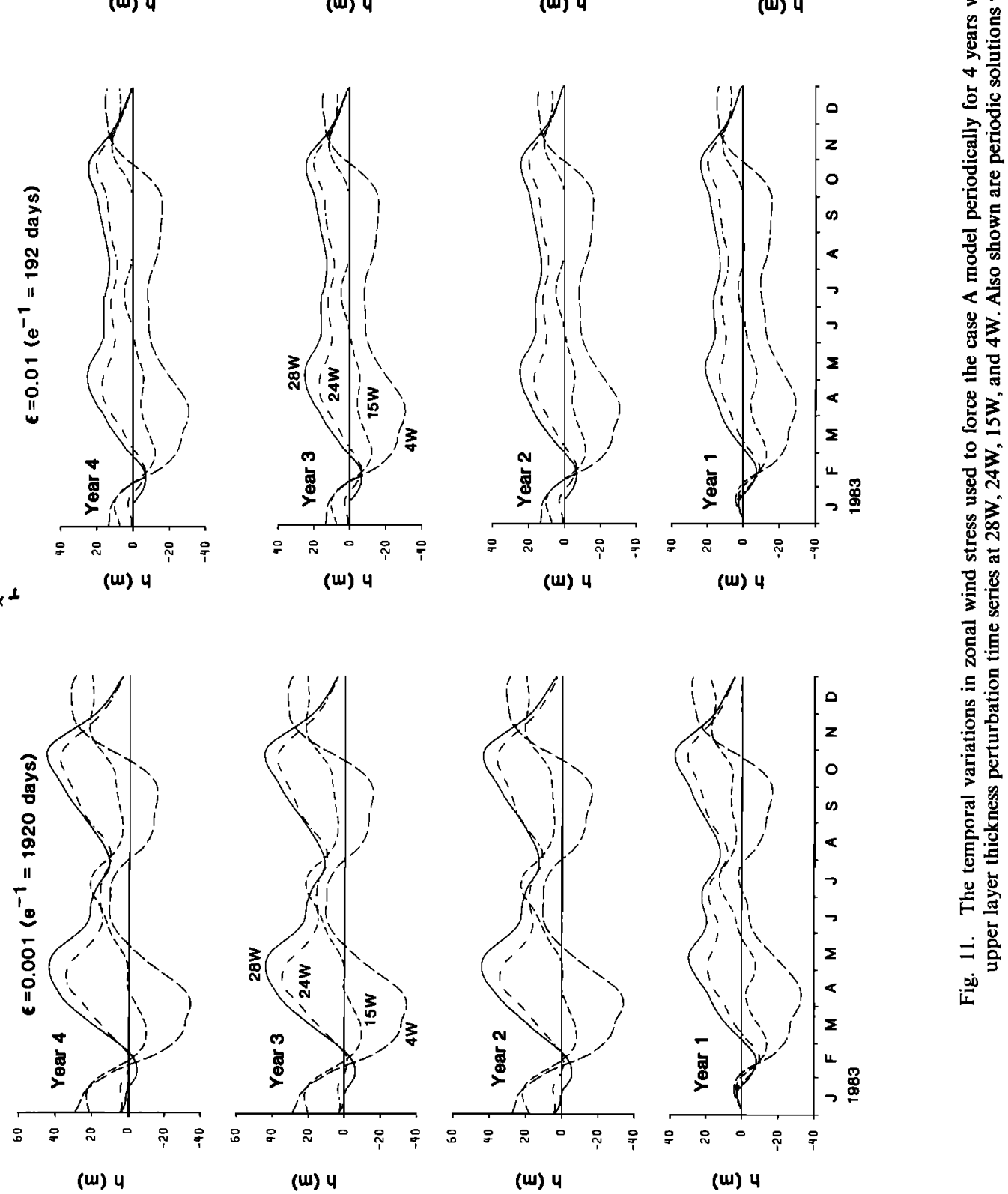

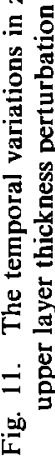



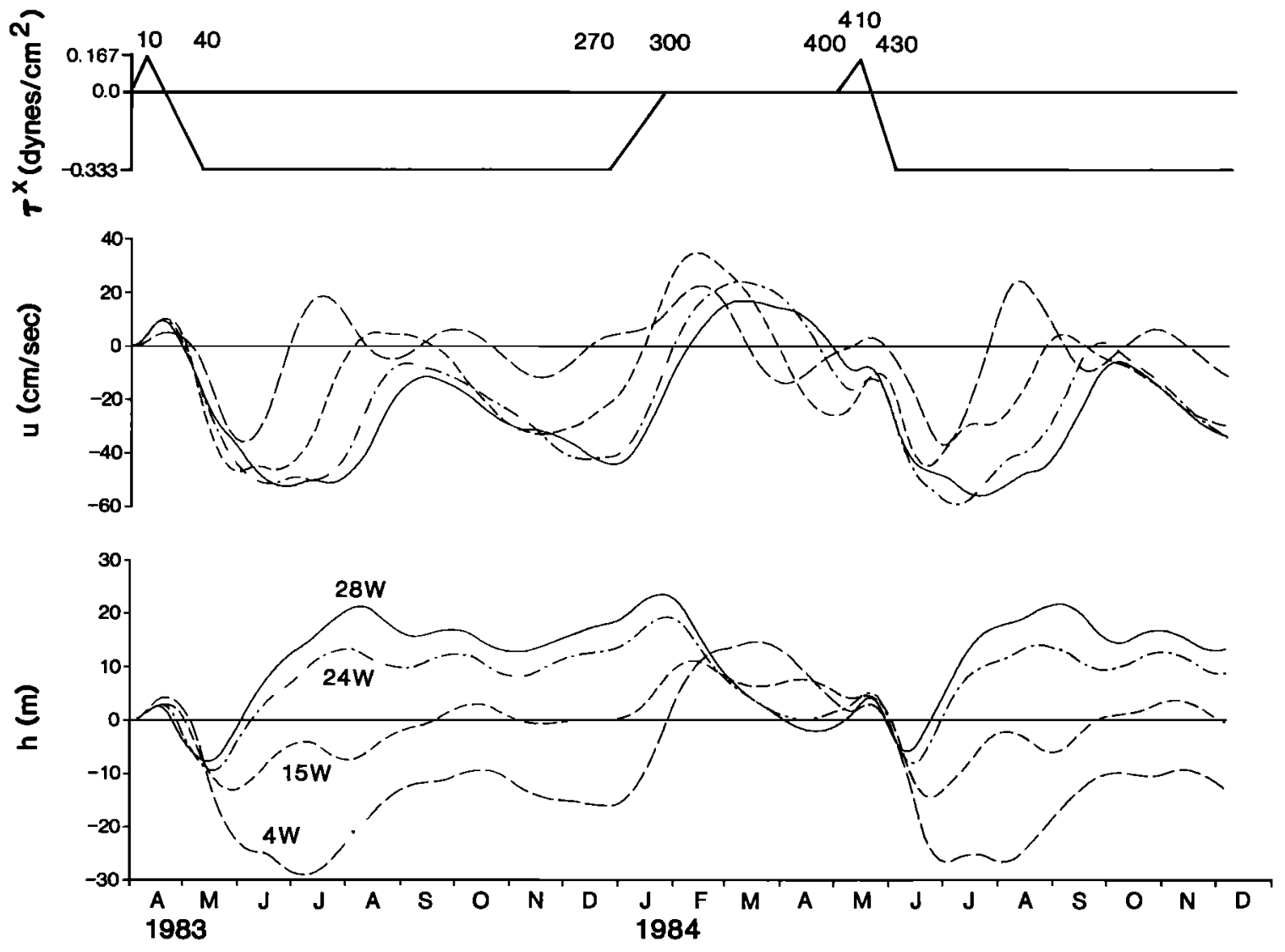

Fig. 12. The temporal variations in zonal wind stress and the upper layer thickness perturbation and zonal velocity component time series calculated at $28 \mathrm{~W}, 24 \mathrm{~W}, 15 \mathrm{~W}$, and $4 \mathrm{~W}$ with $\varepsilon=0.01$ for case $\mathrm{A}$.

April 1, 1983. Westerlies are switched on and allowed to grow linearly for 10 days to a value of $0.166 \mathrm{dyn} / \mathrm{cm}^{2}$. At day 10 the westerlies begin to decrease linearly and reverse to become easterlies, reaching a maximum value of $0.333 \mathrm{dyn} / \mathrm{cm}^{2}$ at day 40. These easterlies are then held constant through day 270 , at which time they decrease linearly to zero at day 300 . The winds remain zero through day 400 . This completes the annual cycle for the first model year. Note that the first model year is longer than a calendar year as observed in 1983. A varying duration is one aspect of the interannual modulation of the annual cycle of wind stress over the equatorial Atlantic Ocean. We begin the second model year at day 400 with linearly increasing westerlies through day 410 , followed by linearly decreasing westerlies reversing to easterlies and reaching a maximum and thereafter constant value at day 430 . The total range in wind stress of $0.5 \mathrm{dyn} / \mathrm{cm}^{2}$ is the same for both
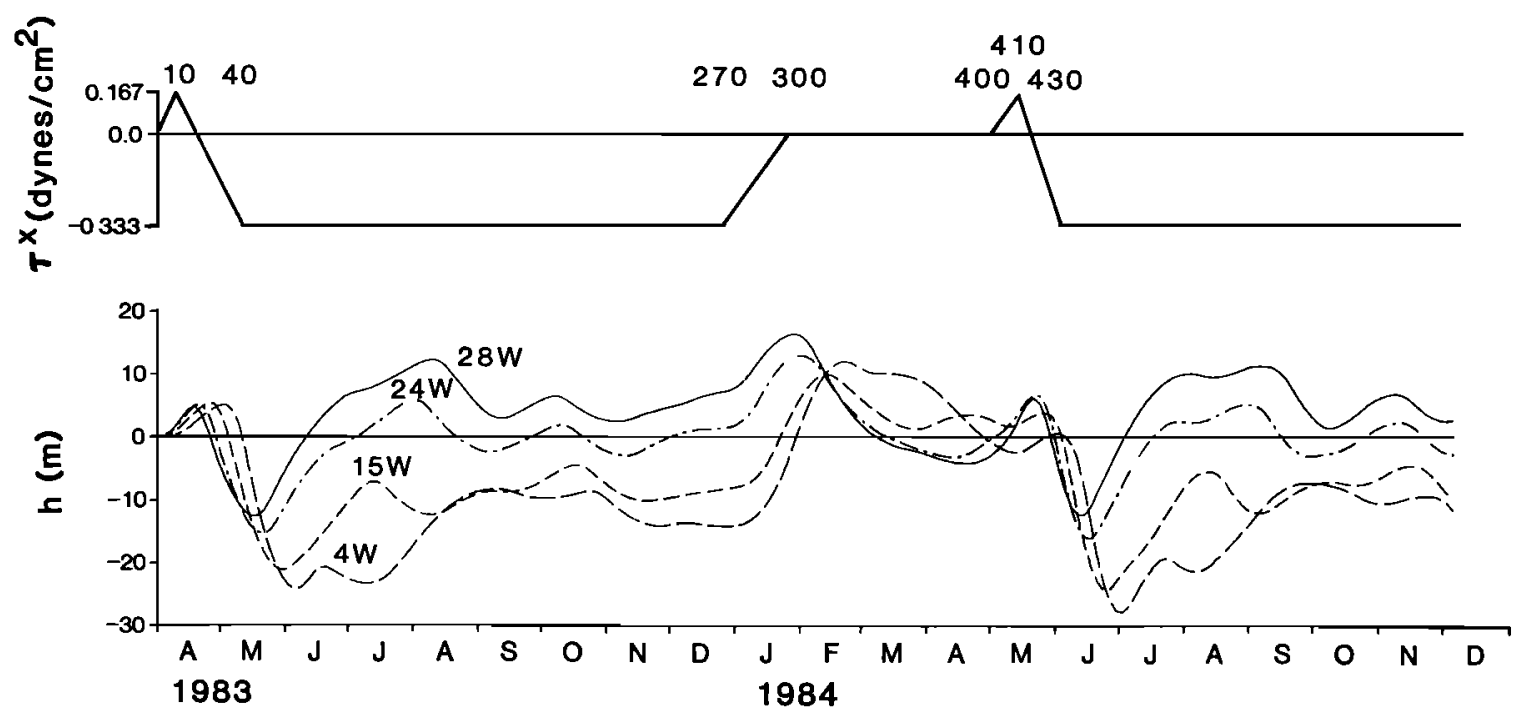

Fig. 13. The temporal variations in zonal wind stress and the upper layer thickness perturbation time series calculated at $28 \mathrm{~W}, 24 \mathrm{~W}, 15 \mathrm{~W}$, and $4 \mathrm{~W}$ with $\varepsilon=0.01$ for case $\mathrm{B}$. 


\section{LONGITUDE}

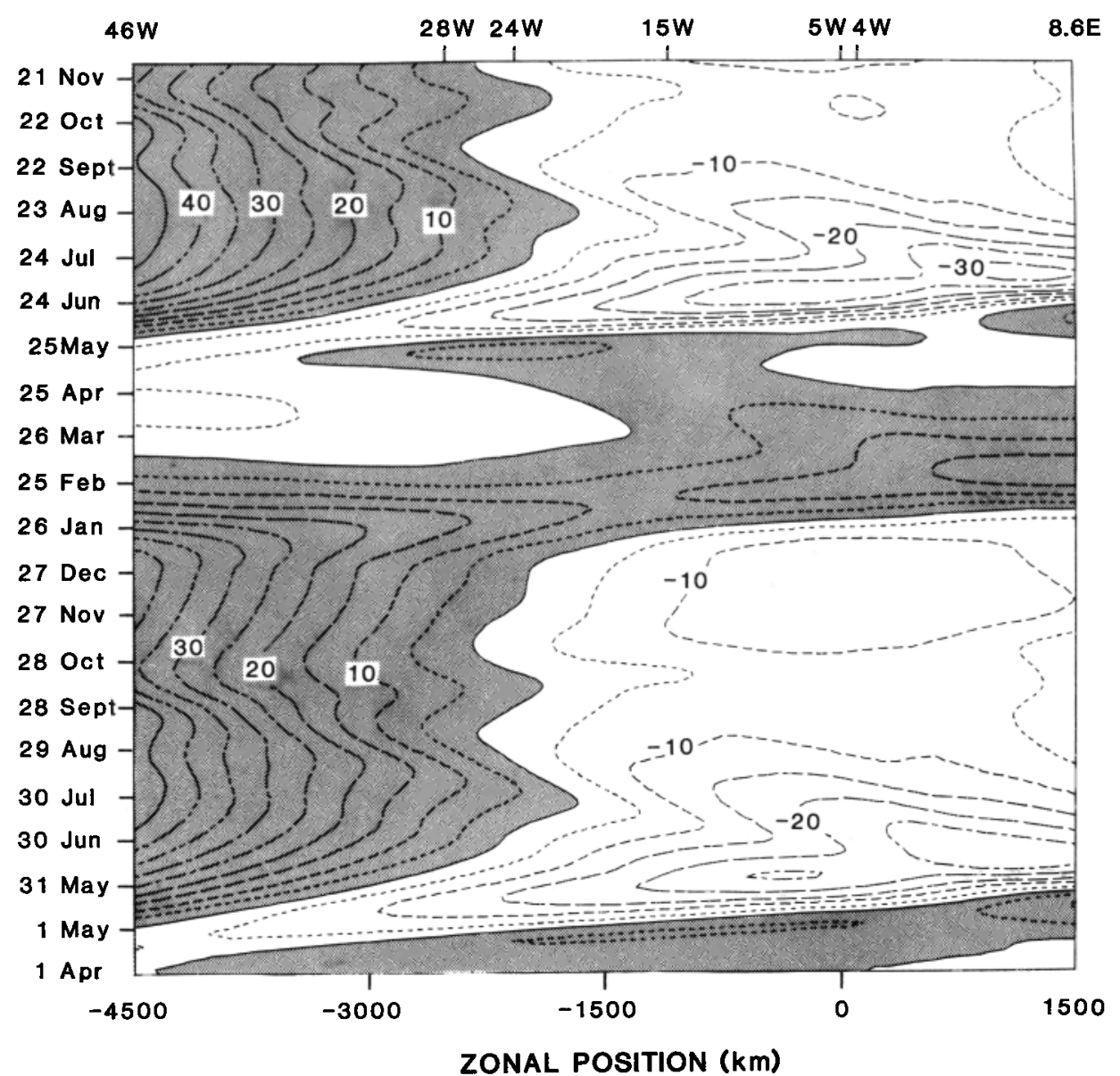

Fig. $14 a$

Fig. 14. Upper layer thickness perturbation as a function of time and longitude along the equator for case $B:(a) c=160$ $\mathrm{cm} / \mathrm{s}$ and $(b) c=140 \mathrm{~cm} / \mathrm{s}$. Stippling denotes positive values.

years; however, the intensification time from westerlies to easterlies in the 1984 model year is 20 days as opposed to 30 days in the 1983 model year. These relative variations in wind stress are chosen as the simplest ones that embody the largescale changes observed. The short-lived westerly pulses are intended to model the equally short-lived wind stress relaxation events that occurred in both years just prior to the springtime intensifications. These intensifications occurred rapidly in both years, with the one in 1984 being somewhat more rapid than the one in 1983 . The wintertime relaxation in easterly wind stress during 1983 occurred over the course of a month or so beginning in mid-December.

\section{Case A: Uniformly Distributed Winds}

Uniformly distributed winds are considered first in order to isolate the temporal response from further complications arising due to the zonal distribution. Figure 12 shows the wind stress variations and the model responses for $h$ and $u$ sampled along the equator at $28 \mathrm{~W}, 24 \mathrm{~W}, 15 \mathrm{~W}$, and $4 \mathrm{~W}$ using a dissipation $e$-folding time of 192 days $(\varepsilon=0.01)$. We will be concerned primarily with $h$ but include $u$ for completeness and for discussion of the model momentum balance later.

The overall response is composed of interference patterns arising from the sum of directly forced and subsequently re- flected waves that are generated with each change in wind stress. Several features of the model response are in qualitative agreement with the ocean observations as shown in Figures 4-7. Consider the easterly wind stress intensifications beginning mid-April 1983 and mid-May 1984. The model response for $h$ consists of sequences of upwelling followed by downwelling that increase systematically to the east both in magnitude and duration. The explanation for this in terms of the forced and reflected waves was given in WT85, where it was also shown that the duration of these sequences depends upon the rapidity over which the easterly wind stress intensifies. The winds during 1984 were observed to intensify more rapidly than those in 1983 . This was modeled using 30 days and 20 days for the intensification times in 1983 and 1984, respectively. The resulting upwelling/downwelling sequence modeled for 1984 was therefore of shorter duration than that modeled for 1983 . While the model winds remain constant for several months after their intensifications, the patterns for $h$ vary due to the reflected waves. One result is a secondary period of upwelling in the Gulf of Guinea from October through December. As discussed in section 3 under the switched-on experiment, this secondary period of upwelling in the model is due to the reflections of the waves that originally gave rise to the primary upwelling/downwelling sequence, and 


\section{LONGITUDE}

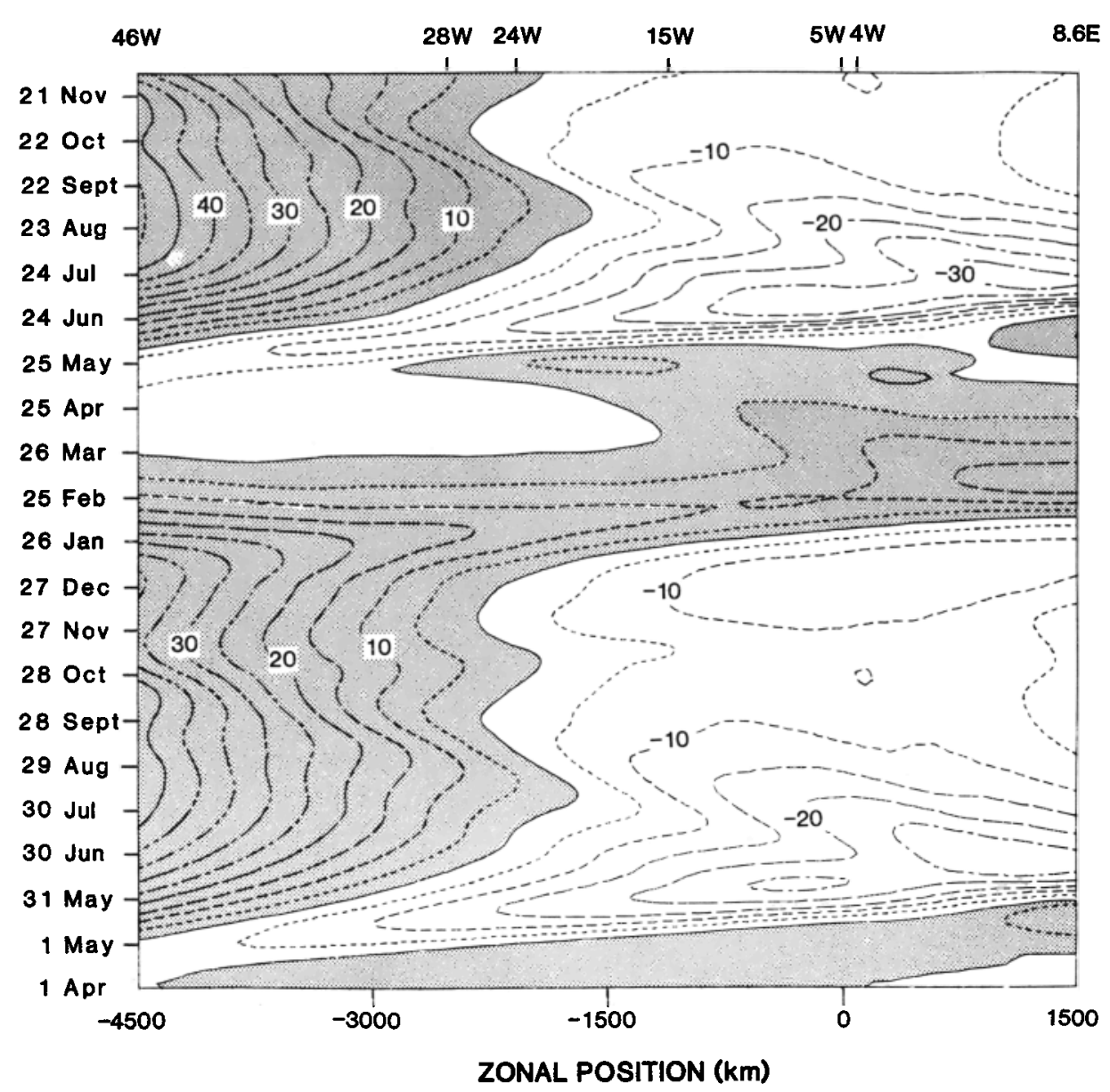

Fig. $14 b$

it is most pronounced in the Gulf of Guinea for the same reason that the primary period of upwelling is most pronounced there.

Now consider the response to the seasonal relaxation in easterly wind stress. The onset in the model was at day $\mathbf{2 7 0}$, corresponding to the end of December. Commensurate with this onset, the model response for $h$ consists of a sequence of downwelling followed by upwelling, which increases systematically to the east both in magnitude and duration. Since the model is linear, the explanation for this relaxation response is similar but opposite to that for the intensification response. Note that the pattern during January shows a peak in the upper layer thickness perturbation at $28 \mathrm{~W}$ at the time when the upper layer thickness is changing most rapidly at $4 \mathrm{~W}$ as observed in the data (see Figures 6 and 7). At subsequent times after the wind stress has diminished to zero, the zonal slope of the interface and its associated pressure gradient reverse. This was also observed as discussed by Weisberg and Weingartner [1986].

Combining the responses due to the seasonal relaxation of easterly wind stress in winter with the subsequent seasonal intensification in spring, we find that the primary upwelling season begins as the response to the relaxation and continues as the response to the intensification. For example, at $4 \mathrm{~W}$ in the model and in the data (Figure 7) the upwelling in 1984 began in March, some 2 months prior to the onset of increas- ing easterlies over the western portion of the basin. Upwelling then continues after the mid-May intensification. In the same way that the upwelling proceeds in two steps, so does the downwelling. Again using $4 \mathrm{~W}$ as an example in the model and in the data, the downwelling due to the intensification began in July 1983 and continued with the relaxation response that began in January 1984. It is the combination of these two major steps in both the upwelling and the downwelling responses that comprises the annual cycle. Under a more slowly varying forcing function these two steps would run together, giving the appearance of a phase-locked annual harmonic.

The model calculation also considered the response to the short-lived easterly wind stress relaxation events immediately preceding the seasonal intensifications. These appear as small peaks in April 1983 and May 1984.

Summarizing the case A results, we find the following qualitative agreements between the data as described in section 2 and the model. Both in 1983 and 1984, sequences of upwelling followed by downwelling were observed after the onsets of the springtime wind stress intensifications. These sequences increased both in magnitude and duration to the east. The sequence in 1984 was slightly shorter than in 1983 , owing to a more rapid intensification in 1984. A sequence of downwelling followed by upwelling increasing systematically to the east both in magnitude and duration was observed after the onset of the 1983 wintertime wind stress relaxation. All of these 


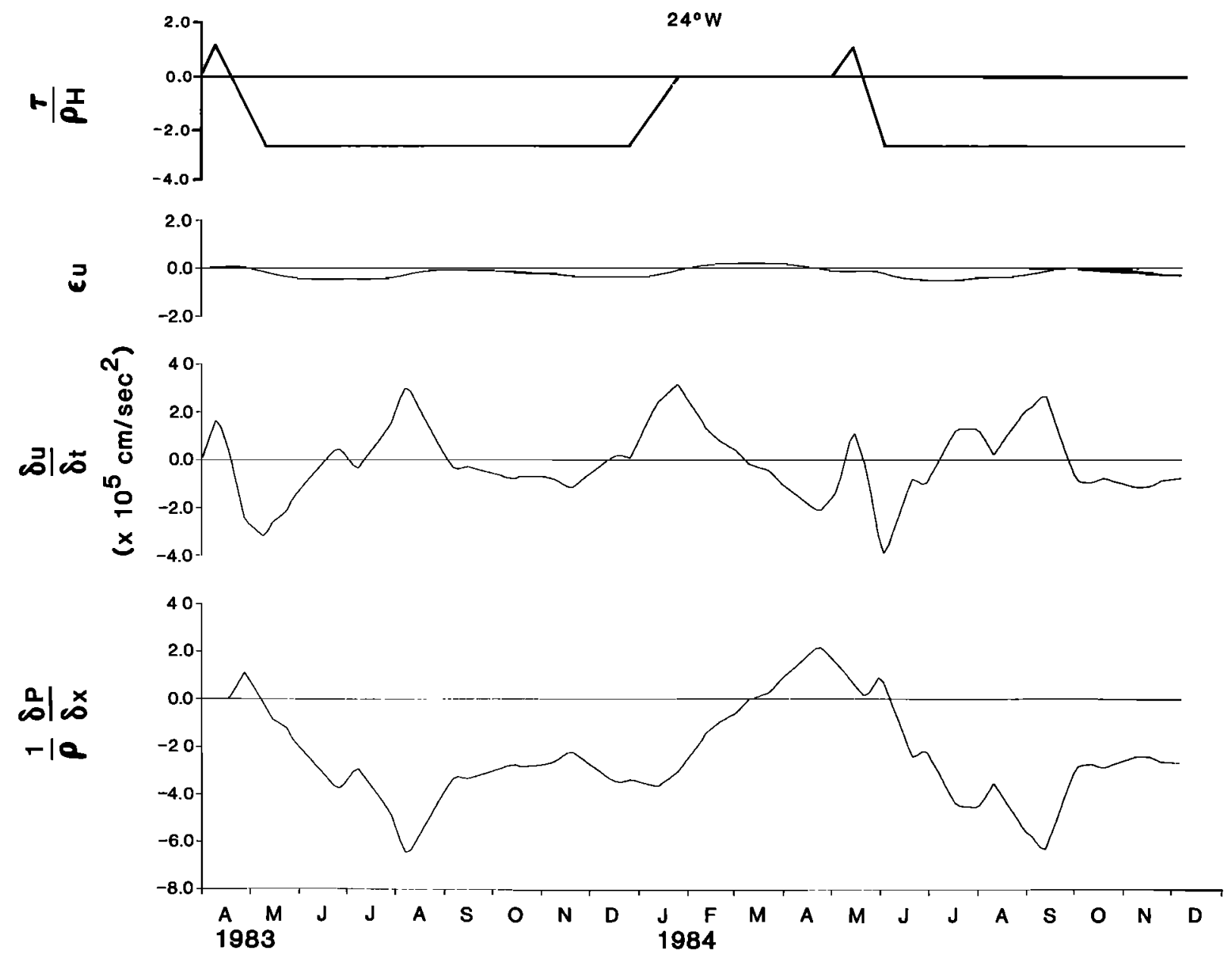

Fig. 15. Time series for the terms in the zonal momentum balance at the equator, $24 \mathrm{~W}$ calculated under case $\mathrm{A}$.

features in the model result as interference patterns between directly forced and reflected waves. As with the previous tests, reduction of the Rayleigh friction parameter here did not qualitatively alter these results.

\section{Case B: Linearly Distributed Winds}

In the equatorial Atlantic where the southeast trade winds veer more easterly to the west, the zonal component of wind stress tends to be maximum and easterly along the Brazilian coast and weak and westerly along the African coast (Figure 3). To investigate the effects of this zonal distribution of wind stress upon the ocean's response, we have chosen a zonally linear distribution with a nodal point at $5 \mathrm{~W}$ as shown in Figure 9. The model was run using the same time dependence and $e$-folding scale as in case $A$, and the results for the upper layer thickness perturbations at $28 \mathrm{~W}, 24 \mathrm{~W}, 15 \mathrm{~W}$, and $4 \mathrm{~W}$ are given in Figure 13.

The overall evolution of the patterns under the linear and uniform wind distributions is essentially the same. It is primarily the time dependence that determines this evolution in the model. However, the linearly distributed winds result in a more sharply defined set of features following the temporal changes in wind stress. This is due to the relative forcing of the Kelvin and Rossby waves by the zonally varying, as opposed to zonally uniform, winds. For example, even the responses to the short-lived relaxation events in April 1983 and May 1984 are accentuated under zonally varying winds.
The pattern evolution for $h$ is shown as a function of longitude along the equator and time in Figure 14a. The development of the response over the first 5 months in this figure was discussed by WT85. Several additional features are now evident in this longer integration. Following the springtime onset of increasing wind stress (easterly over the western three fourths and westerly over the eastern one fourth of the basin) during both years, the systematic evolution of the upwelling response, culminating with maximum values in the Gulf of Guinea, occurs over the entire length of the equator. While the region of minimum $h$, i.e., maximum upwelling, varies with time, it is generally centered upon $5 \mathrm{~W}$, which is consistent with the historical hydrographic data reported by Houghton [1983]. The exceptions to this are over periods of a few weeks during the transitions (e.g., June 1983 and July 1984), when maximum upwelling does extend to the African coast. The location of the maximum upwelling zone in this particular model is due to the interference of the directly forced and reflected waves arising from both the easterly winds to the west and the westerly winds to the east of $5 \mathrm{~W}$. The position of the nodal point in zonal wind stress component along the equator is therefore important in determining the position of maximum upwelling. The zone of secondary upwelling during October through December 1983 is also clearly depicted, with a closed contour in the region corresponding to the Gulf of Guinea.

Along with each major change in wind stress is a rapid 


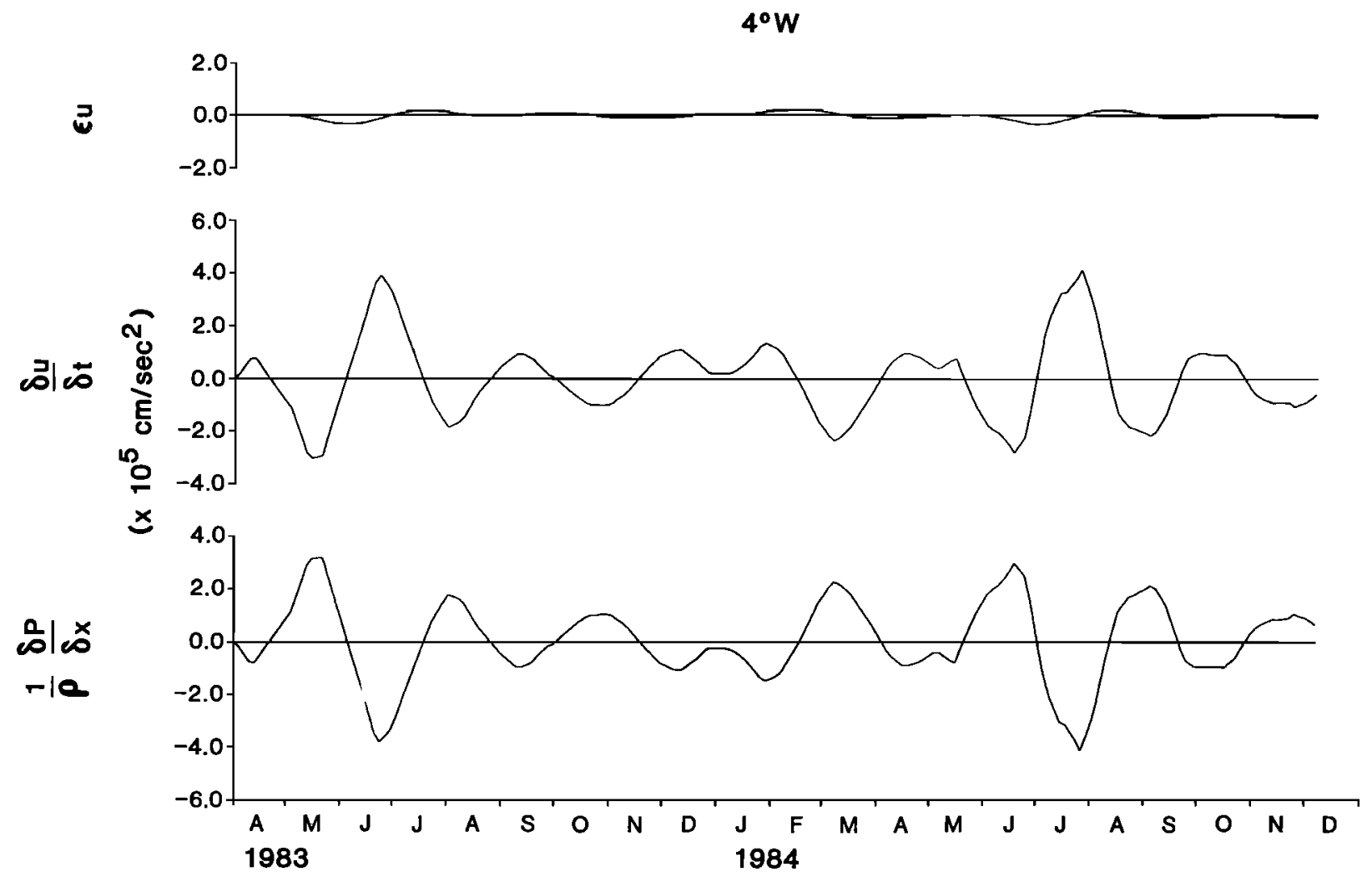

Fig. 16. Time series for the terms in the zonal momentum balance at the equator, $4 \mathrm{~W}$ calculated under case $\mathrm{A}$.

variation in the zonal gradient of $h$ or, equivalently, the zonal pressure gradient. The pressure gradient builds very rapidly following the onset of the wind stress intensification and collapses equally rapidly following the wind stress relaxation. During these periods of change the zonal pressure gradient is highly nonuniform. Also note that a reversal of the zonal pressure gradient from an eastward directed force to a westward directed force occurs across the entire basin after the wintertime wind stress relaxation.

The development and phasing of the interference patterns depend upon both the wind forcing and the reduced-gravity wave speed. Small changes in reduced-gravity wave speed do not significantly alter the results. This is demonstrated in Figure $14 b$ using a speed of $140 \mathrm{~cm} / \mathrm{s}$, commensurate with the second baroclinic mode used by Busalacchi and Picaut [1983] and McCreary et al. [1984].

\section{Momentum Balance}

The terms in the momentum equations are shown at $24 \mathrm{~W}$ and $4 \mathrm{~W}$ under the case $A$ wind stress forcing function in Figures 15 and 16, respectively. Figure 15 contains four time series: the wind stress as a body force over the upper layer, the Rayleigh frictional damping, the local acceleration, and the local zonal pressure gradient. The error in the summation of the terms relative to any individual term was typically $2 \%$ and never exceeded $5 \%$. These relative errors suggest that the long wave approximation in this equatorially trapped wave model is not a limiting factor. Friction in the model calculation is locally unimportant for the momentum balance. It is important, however, in slowly damping out the reflected wave modes, since it enters the solution in the form exp $(-\varepsilon t)$. Upon the onset of the wind stress at $t=0$, we observe a local acceleration for approximately 2 weeks prior to the establishment of any zonal pressure gradient. This is a Yoshida jet [Yoshida, 1959; O'Brien and Hurlburt, 1974], wherein the balance is between the wind stress and the local acceleration. When the wind stress becomes easterly, we observe a westward acceleration continuing until the zonal pressure gradient begins to establish. In its tendency toward balancing the wind stress, the pressure gradient overshoots, resulting in an eastward acceleration, which in turn causes the westward surface current to decrease rapidly, as shown in Figure 12. Following the overshoot, the pressure gradient settles into an approximate equilibrium with the wind stress and remains so until the next major change in wind stress at the end of December 1983. The process just described then occurs in reverse, resulting in a westward directed pressure force in April 1984 due to the overshoot following the wintertime wind stress relaxation. Therefore over most of the annual cycle, both the pressure gradient and the currents are in states of transition. It is only over a brief period of time when the pressure gradient is in approximate balance with the wind stress that a state of near equilibrium is realized.

The results at $4 \mathrm{~W}$ shown in Figure 16 are of different character, since the case A distributed wind stress is zero at this longitude. Again friction is locally unimportant, and we observe an inverse relationship between the pressure gradient and the local acceleration in maintaining the momentum balance. Being that the wind stress is zero, there is no Yoshida jet, and the currents simply respond to the local pressure gradient.

Each change of pressure gradient in this model depends upon either a change in the wind stress or a wave front passage. Figure 17 shows the zonal pressure gradient time series sampled from the model at $34 \mathrm{~W}, 24 \mathrm{~W}$, and $10 \mathrm{~W}$ relative to the case A wind stress variations. While the overshoots for 


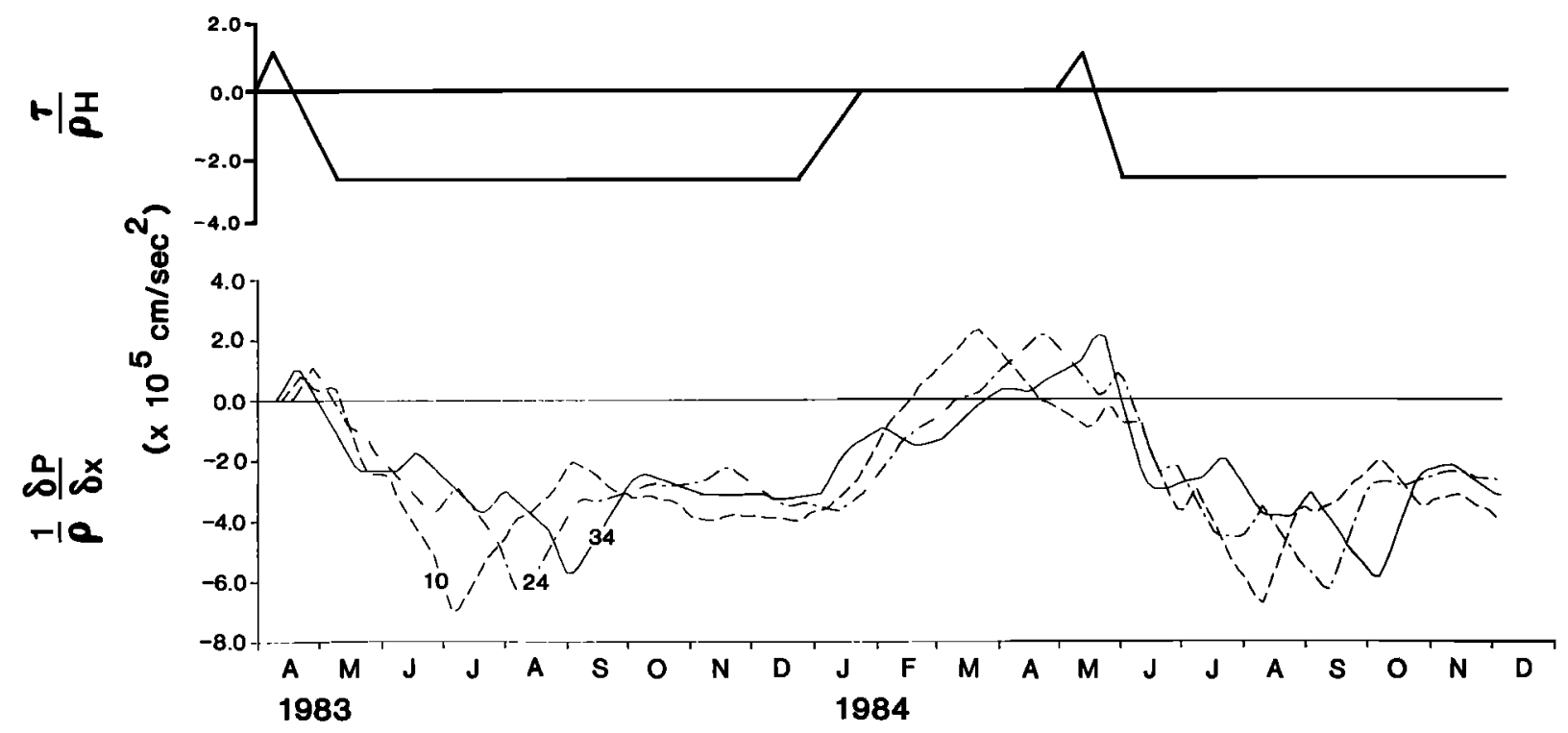

Fig. 17. Zonal pressure gradient time series calculated along the equator at $34 \mathrm{~W}, 24 \mathrm{~W}$, and $10 \mathrm{~W}$ under case $\mathrm{A}$.

both the springtime intensification and wintertime relaxation responses are clearly evident at all longitudes, they occur systematically at different times. Since the overshoot is not completed until the first-mode Rossby wave reflected from the eastern boundary propagates past the point in question, it follows that the pressure gradient attains its maximum value first to the east and successively later to the west. Therefore during the transitions following the major wind stress changes, the pressure gradient along the equator is highly nonuniform. A nearly uniform pressure gradient is attained only after the thermocline has had time to adjust, which in Figure 17, occurs between October and December 1983.

\section{Model Pressure Gradient Comparison}

The pressure gradient time series shown in Figures 15, 16, and 17 were calculated as partial derivatives at particular points. Such calculations are not generally possible from field data, since instruments are spaced over finite intervals. The baroclinic response of the zonal pressure gradient along the equator at a given depth consists of a surface slope induced portion plus a portion due to the sloping isopycnals. Weisberg and Weingartner [1986] calculated the baroclinic response of the zonal pressure gradient due to the sloping isopycnals using temperature time series from the SEQUAL and FOCAL moorings. Figure 18 compares the zonal pressure gradient time series calculated by finite difference between $28 \mathrm{~W}$ and $4 \mathrm{~W}$ from the case $\mathrm{B}$ model results and from the observed isopycnal slopes integrated to $75-\mathrm{m}$ depth. Neglecting the small high-frequency variations in the data, we find that the model and the data-calculated pressure gradient time series mirror each other for all of the features associated with the large-scale changes in zonal wind stress. We observe this for the responses to (1) the short-lived relaxation events in April 1983 and May 1984, (2) the springtime intensifications during both years including the overshoots, (3) the approach to relatively steady values between October and December 1983, and (4) the wintertime relaxation. These agreements follow from the timing of the principal features as calculated by the model and as observed in the vertically integrated heat content at $28 \mathrm{~W}$ and $4 \mathrm{~W}$.
While the model and data finite difference calculations agree, they differ in several aspects from the pressure gradients calculated by partial differentiation at specific locations, and it is this latter quantity that is relevant to the momentum balance. These differences arise due to wave propagation occurring over the transition periods following large-scale changes in wind stress. Consequently, it may be difficult to relate finite difference calculated pressure gradients to local rates of change of momentum during these transition periods.

The nonuniform behavior of and the differences between the locally and finite difference calculated zonal pressure gradients during the transitions are comparable with the zonal surface slope calculations presented by Katz et al. [1986] using data from the SEQUAL equatorial inverted echo sounder array. A linear regression was employed to calculate the surface slope as a function of time using records from $34 \mathrm{~W}, 28 \mathrm{~W}, 20 \mathrm{~W}$, and $10 \mathrm{~W}$ with error bars determined from the regression coefficients. The error bars were generally largest during the transitions and smallest after the thermocline had adjusted.

\section{Discussion}

Monotonic changes to constant values were used in section 4 to model the springtime intensifications and the wintertime relaxation in zonal wind stress. While high- and low-wind seasons are distinctive features of the SPPR data, also present in Figure 2 are high-frequency oscillations with amplitudes approaching half that of the annual cycle. What effects do these oscillations have upon the ocean's response? Spectral analyses of the SPPR and 4W wind records (S. Garzoli and C. Colin, personal communication, 1986) show a peak centered around a 15-day period. To investigate the effects of these oscillations, a sawtooth variation with an amplitude equal to half the annual cycle was added to the case $B$ wind stress forcing function during the high-wind seasons. This was done for sawtooth periodicities of 15 and 30 days, and the results are shown in Figure 19. The overall character of the annual cycle remains unchanged with the exception of high-frequency oscillations superimposed upon it. These are similar for the 30-day period case to the short-lived relaxation events as 


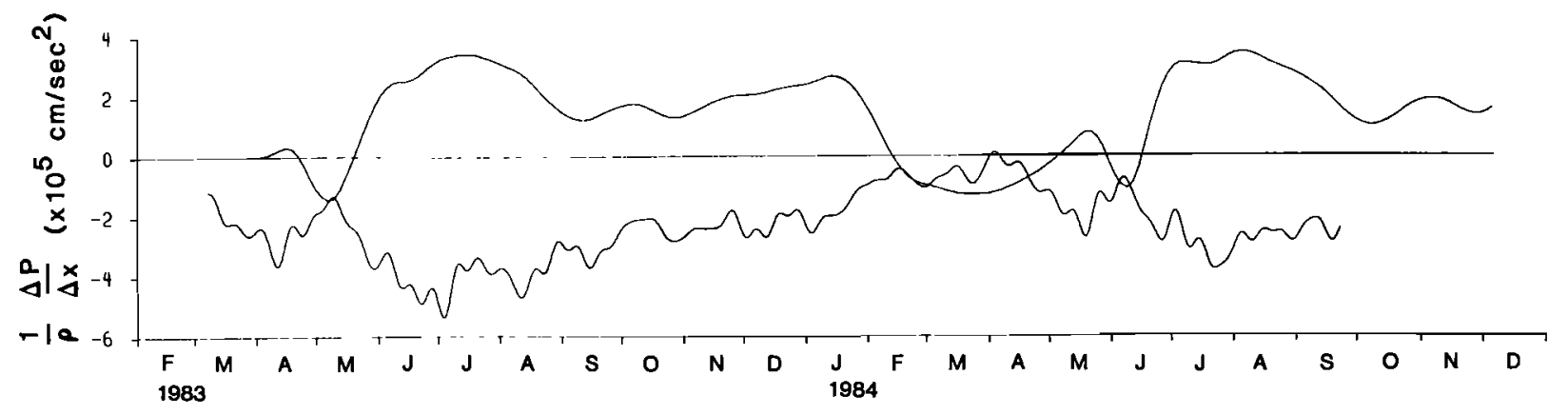

Fig. 18. Comparison between zonal pressure gradient time series calculated by finite difference between $28 \mathrm{~W}$ and $4 \mathrm{~W}$ from the case B model results and from the data of Weisberg and Weingartner [1986].

modeled in Figures 12 and 13, which if extrapolated as a sawtooth, would have had a periodicity of $\mathbf{4 0}$ days. The amplitude of the response is frequency dependent, since it takes a finite amount of time for the response to develop. Thus the higher the frequency (in this long wave model), the smaller the response, since successive variations tend to cancel out and the addition of spatial structure would have further reduced the response for the same reason. Referring back to Figures 6 and 7 , we see that the high-frequency fluctuations observed in the thermocline are similarly small relative to the annual cycle. At higher frequencies than these, inertia-gravity waves would eventually provide a mechanism for an increased ocean response; however, relative to the annual cycle, we do not observe appreciable energy at inertia-gravity wave time scales in Figures 4 or 5 either.

Throughout the text we have described the various responses as patterns arising from the interference of the directly forced and subsequently reflected waves originating with each change in wind stress. The patterns are initially shaped, depending upon the manner in which the wind stress varies. The patterns are further developed by the reflected waves. While these patterns all appear to propagate (some east and some west), none of them can be classified as individual equatorially trapped Kelvin or Rossby waves. The annual cycle of the thermocline along the equator in the Atlantic can be described as a series of these patterns, and depending upon which features of the annual cycle are of interest, the winds over the entire equatorial extent of the basin are important in the pattern development. For example, the position of maximum upwelling in the Gulf of Guinea, generally centered upon $5 \mathrm{~W}$ in the model, depends not only on the easterly winds to the west of that position but also on the westerly winds to the east.

Our approach has been to use the simplest applicable model forced by the simplest representative wind stress distribution in order to study the patterns of thermocline variability. The benefit of this approach is that it affords an understanding of the basis for these patterns. The limitation is that it excludes other physical processes that may be important and it necessitates a simplified wind stress. Our comparisons between the data and the model results have therefore been selective, since it is only the major features of the annual cycle that we could hope to account for qualitatively with an approach of this type. Further quantitative simulation including extra-equatorial effects would require a more complete model

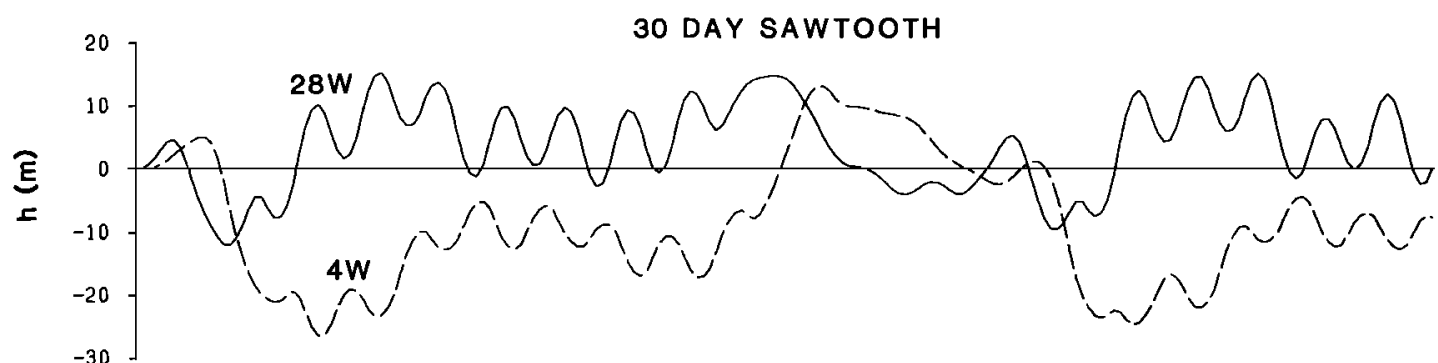

15 DAY SAWTOOTH

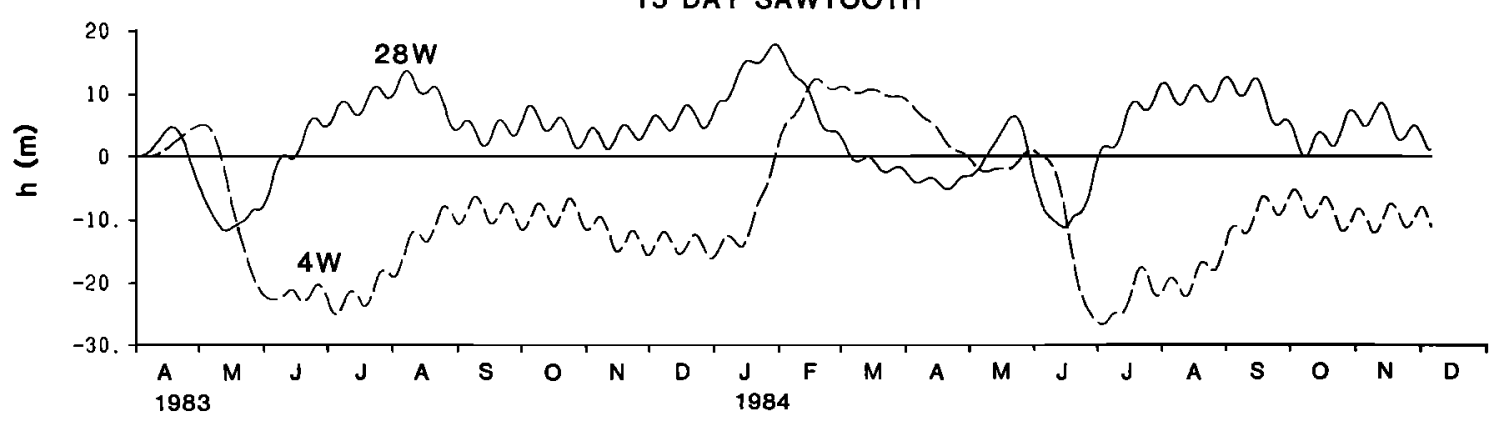

Fig. 19. Upper layer thickness perturbation time series along the equator at $28 \mathrm{~W}$ and $4 \mathrm{~W}$ calculated under case $B$ with the addition of high-frequency wind stress oscillations added during the high-wind seasons. Two examples are given using sawtooth periodicities of 15 and 30 days, each having amplitudes equal to half that of the annual cycle. 
driven by a similarly complete wind stress field. A drawback to this, however, is that it would be more difficult to interpret the results.

\section{Summary}

The sea surface temperature, the thermocline, and the currents of the equatorial Atlantic Ocean undergo distinct annual cycles in response to the surface trade winds. Based upon climatological averages of the historical ship observed winds, surface drifts, and surface and subsurface hydrographic data sets, a description of the annual cycle has emerged with the ocean variables being nearly in phase with the zonal component of wind stress. The SEQUAL experiment and the FOCAL program were initiated to provide a data set for further understanding the annual cycle in the equatorial Atlantic. We have described in this paper several aspects of the SEQUAL/FOCAL basin-wide and synoptic data that were found to differ from the climatologically averaged description and have attempted to reconcile these differences in a qualitative manner by using a wind-forced equatorial ocean model constructed in the simplest way that would allow for including the large-scale zonal wind stress variations as observed along the equator. Our data description has focused upon the annual variations of the equatorial thermocline from February 1983 through September 1984, and the model employed was an analytical, linear, reduced-gravity, equatorial long wave model forced by temporally and spatially varying zonal wind stress. While incomplete at least in its linear and single-layer reduced-gravity formulation, justification for a model of this type used to study the overall thermocline variations is based on findings from more complete multilayer and multilevel linear and nonlinear numerical model runs, which have shown that the vertically integrated heat or dynamic height responses are insensitive at least qualitatively to the more complicated physics.

In contrast to the slow variations of zonal wind stress in the climatologically averaged data, the winds during 1983-1984 were observed to vary rapidly, with a springtime intensification to relatively strong values and a wintertime relaxation to relatively weak values. Following the onset of intensification, the thermocline was observed to undergo a sequence of upwelling followed by downwelling and, conversely, following the onset of relaxation. These sequences of thermocline variability increased systematically to the east both in magnitude and duration over the entire portion of the equator sampled. No indication of a pivot point, as described in the climatology, was observed.

The model was tested using switched-on and periodic forcing functions before being run, with a zonal wind stress distribution varying both along the equator and in time in a simplified but representative manner of the large-scale seasonal variations. The model produced many of the salient features of the thermocline variability as described, including (1) the systematic upwelling/downwelling sequences observed following the springtime intensifications in both 1983 and 1984, (2) the slightly shorter duration for this sequence in 1984 compared with 1983 , (3) the systematic downwelling/upwelling sequence following the wintertime relaxation, (4) the region of maximum upwelling along the equator generally centered upon $5 \mathrm{~W}$, and (5) the short-lived pulses following equally short-lived springtime relaxation events. Both the model and the observations suggest that the equatorial upwelling proceeds in two stages, beginning with the relaxation of wind stress from the previous year and continuing with the intensification in the present year.

The behavior of the zonal pressure gradient along the equator was also investigated both as locally and finite difference calculated partial derivatives. The model-derived zonal pressure gradient time series between $28 \mathrm{~W}$ and $4 \mathrm{~W}$ was found to be a mirror image of that calculated from the moored temperature data. Following the wind stress transitions, the zonal pressure gradient overshoots its intended equilibrium and is zonally nonuniform.

The differences between the climatological description of the annual cycle and the SEQUAL/FOCAL observations when compared with the analytical calculations presented here suggest that these differences are primarily due to the rapidly varying nature of the zonal wind stress in any given year versus the slowly varying climatology. While the model excludes many aspects of the physics that are thought to be important, it does qualitatively reproduce the observed patterns of the annual cycle, and therefore it provides some guidance in interpreting simulations performed using more complete and hence more complicated numerical models.

Acknowledgments. Support for this work was provided by the Oceanography Section, National Science Foundation, under grants OCE-8211848 and OCE-8515869. S. Garzoli, D. Halpern, and R. Payne kindly provided data for inclusion herein. C. Colin provided both data and many helpful discussions.

\section{References}

Busalacchi, A. J., and J. Picaut, Seasonal variability from a model of the tropical Atlantic Ocean, J. Phys. Oceanogr., 13, 1564-1588, 1983.

Cane, M., and E. S. Sarachik, Forced baroclinic ocean motions, I, The linear equatorial unbounded case, J. Mar. Res., 34, 629-666, 1976.

Cane, M., and E. S. Sarachik, Forced baroclinic ocean motions, II, The linear equatorial bounded case, J. Mar. Res., 35, 395-432, 1977.

Cane, M., and E. S. Sarachik, The response of a linear baroclinic equatorial ocean to periodic forcing, J. Mar. Res., 39, 651-693, 1981.

du Penhoat, Y., and A. M. Treguier, Sea surface dynamic height topography and the North Equatorial Countercurrent as inferred from a linear model, Geophys. Res. Lett., 11, 799-801, 1984.

Garzoli, S. L., and E. J. Katz, The forced annual reversal of the Atlantic North Equatorial Countercurrent, J. Phys. Oceanogr., 13, 2082-2090, 1983.

Garzoli, S. L., E. J. Katz, H. J. Panitz, and P. Speth, In situ wind measurements in the equatorial Atlantic during 1979, Oceanol. Acta, 5, 281-288, 1982.

Gent, P. R., K. O'Neill, and M. Cane, A model of the semiannual oscillation in the equatorial Indian Ocean, J. Phys. Oceanogr., 13, $2148-2160,1983$.

Gill, A. E., Some simple solutions for heat induced tropical circulations, Q. J. R. Meteorol. Soc., 106, 447-462, 1980.

Gill, A. E., and A. J. Clarke, Wind induced upwelling, coastal currents, and sea level changes, Deep Sea Res., 21, 325-345, 1974.

Hastenrath, S., and P. J. Lamb, Climatic Atlas of the Tropical Atlantic and Eastern Pacific Ocean, 25 pp. and 9 charts, University of Wisconsin Press, Madison, 1977.

Heckley, W. A., and A. E. Gill, Some simple analytical solutions to the problem of forced equatorial long waves, $Q . J . R$. Meteorol. Soc., 110, 203-217, 1984.

Hellerman, S., Charts of the variability of the wind stress over the tropical Atlantic, Deep Sea Res., 26, suppl. II, 63-75, 1979.

Houghton, R. W., Seasonal variation of the subsurface thermal structure in the Gulf of Guinea, J. Phys. Oceanogr., 13, 2070-2081, 1983.

Hurlburt, H. E., J. C. Kindle, and J. J. O'Brien, A numerical simulation of the onset of El Niño, J. Phys. Oceanogr., 6, 621-631, 1976.

Katz, E. J., Dynamic topography of the sea surface in the equatorial Atlantic, J. Mar. Res., 30, 53-63, 1981.

Katz, E. J., P. Hisard, J. M. Verstraete, and S. L. Garzoli, Annual 
change of the sea surface slope along the equator of the Atlantic Ocean in 1983 and 1984, Nature, 322, 245-247, 1986.

McCreary, J. P., Eastern tropical ocean response to changing wind systems: With application to El Niño, J. Phys. Oceanogr., 6, 632645, 1976.

McCreary, J. P., J. Picaut, and D. W. Moore, Effects of remote annual forcing in the eastern tropical Atlantic Ocean, J. Mar. Res., 42, 45-81, 1984.

Merle, J., Atlas hydrologique saisonnier de l'océan Atlantique intertropical, Trav. Doc. ORSTOM, 82, 1978.

Merle, J., Seasonal heat budget in the equatorial Atlantic Ocean, $J$. Phys. Oceanogr., 10, 464-469, 1980.

Merle, J., and S. Arnault, Seasonal variability of the surface dynamic topography in the tropical Atlantic Ocean, J. Mar. Res., 43, 267$288,1985$.

Moore, D. W., Planetary gravity waves in an equatorial ocean, Ph.D. thesis, 210 pp., Harvard Univ., Cambridge, Mass., 1968.

Moore, D. W., and S. G. H. Philander, Modelling of the tropical oceanic circulation, in The Sea, vol. 6, edited by E. Goldberg et al., pp. 319-361, Wiley-Interscience, New York, 1977.

O'Brien, J. J., and H. E. Hurlburt, Equatorial jet in the Indian Ocean: Theory, Science, 184, 1075-1077, 1974.

Payne, R., Surface wind measurements in SEQUAL I, Geophys. Res. Lett., 11, 719-721, 1984.

Philander, S. G. H., The response of equatorial oceans to a relaxation of the trade winds, J. Phys. Oceanogr., 11, 176-189, 1981.

Philander, S. G. H., and R. C. Pacanowski, The generation and decay of equatorial currents, J. Geophys. Res., 85, 1123-1136, 1980.

Philander, S. G. H., and R. C. Pacanowski, Response of equatorial oceans to periodic forcing, J. Geophys. Res., 86, 1903-1916, 1981.

Philander, S. G. H., and R. C. Pacanowski, Simulation of the seasonal cycle in the tropical Atlantic Ocean, Geophys. Res. Lett., 11, 802804, 1984.
Philander, S. G. H., and R. C. Pacanowski, A model of the seasonal cycle in the tropical Atlantic Ocean, J. Geophys. Res., 91, 14,19214,206, 1986.

Servain, J., J. Picaut, and J. Merle, Evidence of remote forcing in the equatorial Atlantic Ocean, J. Phys. Oceanogr., 12, 457-463, 1982.

Weisberg, R. H., Seasonal adjustments in the equatorial Atlantic during 1983 as seen by surface moorings, Geophys. Res. Lett., I1, 733-735, 1984.

Weisberg, R. H., and T. Y. Tang, Equatorial ocean response to growing and moving wind systems with application to the Atlantic, $J$. Mar. Res., 41, 461-486, 1983.

Weisberg, R. H., and T. Y. Tang, On the response of the equatorial thermocline in the Atlantic Ocean to the seasonally varying trade winds, J. Geophys. Res., 90, 7117-7128, 1985.

Weisberg, R. H., and T. J. Weingartner, On the baroclinic adjustment of the zonal pressure gradient in the equatorial Atlantic Ocean, $J$. Geophys. Res., 91, 11,717-11,725, 1986.

Yoshida, K., A theory of the Cromwell current (the Equatorial Undercurrent) and of the equatorial upwelling-An interpretation in a similarity to the coastal circulation, J. Oceanogr. Soc. Jpn., 15, $1-13,1959$.

Zebiak, S. E., A simple atmospheric model of relevance to El Niño, $J$. Atmos. Sci., 39, 2017-2027, 1982.

T. Y. Tang and R. H. Weisberg, Department of Marine Science, University of South Florida, 140 Seventh Avenue South, St. Petersburg, FL 33701. 